\title{
A trimeric human angiotensin-converting enzyme 2 as an anti-SARS-CoV-2 agent
}

\author{
Tianshu Xiao ${ }^{1,2}$, Jianming Lu3 ${ }^{3}$, Jun Zhang ${ }^{1,2}$, Rebecca I. Johnson ${ }^{(4}{ }^{4}$, Lindsay G. A. McKay ${ }^{4}$, \\ Nadia Storm ${ }^{4}{ }^{4}$, Christy L. Lavine ${ }^{5}$, Hanqin Peng1, Yongfei Cai ${ }^{1}{ }^{1,2}$, Sophia Rits-Volloch', Shen Lu³, \\ Brian D. Quinlan ${ }^{6}$, Michael Farzan ${ }^{6}{ }^{6}$, Michael S. Seaman ${ }^{5}$, Anthony Griffiths ${ }^{4}$ and Bing Chen $\mathbb{1}^{1,2} \bowtie$
}

\begin{abstract}
Effective intervention strategies are urgently needed to control the COVID-19 pandemic. Human angiotensin-converting enzyme 2 (ACE2) is a membrane-bound carboxypeptidase that forms a dimer and serves as the cellular receptor for severe acute respiratory syndrome coronavirus 2 (SARS-CoV-2). ACE2 is also a key negative regulator of the renin-angiotensin system that modulates vascular functions. We report here the properties of a trimeric ACE2 ectodomain variant, engineered using a structure-based approach. The trimeric ACE2 variant has a binding affinity of $\sim 60 \mathrm{pM}$ for the spike protein of SARS-CoV-2 (compared with $77 \mathrm{nM}$ for monomeric ACE2 and 12-22 $\mathrm{nM}$ for dimeric ACE2 constructs), and its peptidase activity and the ability to block activation of angiotensin II receptor type 1 in the renin-angiotensin system are preserved. Moreover, the engineered ACE2 potently inhibits SARS-CoV-2 infection in cell culture. These results suggest that engineered, trimeric ACE2 may be a promising anti-SARS-CoV-2 agent for treating COVID-19.
\end{abstract}

$\mathrm{T}$ he current COVID-19 pandemic, caused by SARS-CoV-2, has infected more than 29 million people worldwide, leading to over 900,000 deaths, with devastating socio-economic impacts. Effective intervention strategies are urgently needed to control the pandemic.

Since the outbreak of the virus, several therapeutic approaches have been evaluated in the hope of providing a viable treatment for COVID-19. First, convalescent sera from individuals recovered from the infection were used with encouraging results ${ }^{1-3}$, but also some drawbacks (for example, batch variations, possible blood-borne pathogens and blood-type matching). Second, patient-derived, potently neutralizing monoclonal antibodies have been isolated, which could provide a more powerful passive immunotherapy than convalescent sera ${ }^{4-7}$. Third, structure-guided design of peptide-based viral entry inhibitors has yielded promising leads in in vitro assays ${ }^{8,9}$; their efficacy requires further clinical evaluation. Fourth, known drugs or drug candidates, including remdesivir, favipiravir and ribavirin (viral RNA polymerase inhibitors); lopinavir and ritonavir (viral protease inhibitors); as well as hydroxychloroquine, corticosteroids and interferons (with more complicated antiviral mechanisms), have been repurposed as COVID-19 therapuetics ${ }^{10,11}$. Among them, remdesivir has received Emergency Use Authorizations from the US Food and Drug Administration, while hydroxychloroquine has been shown to be ineffective ${ }^{12}$. Finally, many new therapeutic candidates are in various stages of development (refs. ${ }^{13,14}$; https://www.bio.org/policy/human-health/ vaccines-biodefense/coronavirus/pipeline-tracker). While the infection resolves on its own in most asymptomatic and mild cases over time, COVID-19 in severe cases appears to progress in two phases-initial active viral replication in the respiratory system and subsequent excessive immune responses leading to multiple organ failure and possible death ${ }^{15}$. Thus, antivirals alone may be insufficient to change the course of disease progression for the population that needs intervention the most if administrated too late.

Human ACE2 is the cellular receptor for SARS-CoV-2 and binds the receptor-binding domain (RBD) of the spike (S) protein of the virus to promote viral entry into the host cells and initiate infec$\operatorname{tion}^{16,17}$. The interactions between soluble ACE2 and SARS-CoV-2 RBD have been studied extensively within a very short period of time ${ }^{18-20}$. The intact ACE2 is a type I membrane glycoprotein containing an extracellular ectodomain that has metallopeptidase activity. Its neck domain near the transmembrane anchor mediates dimerization ${ }^{20}$. ACE2 is also a key negative regulator of the reninangiotensin system (RAS) - a major hormone system, conserved in mammals and some other vertebrate animals, for modulating vascular function ${ }^{21,22}$. The RAS controls extracellular fluid volume and blood pressure homeostasis by regulating the levels of renin and angiotensins in the circulation. Renin cleaves angiotensinogen to release angiotensin I (Ang I), which can be further processed by angiotensin-converting enzyme (ACE) into angiotensin II (Ang II) - a vasoconstrictive peptide that raises blood pressure and increases the extracellular fluid volume in the body by activating the Ang II receptors, including angiotensin II receptor type 1 (ATIR) ${ }^{23}$. ACE2 primarily converts Ang II to angiotensin-(1-7) (Ang 1-7), which is a vasodilator, thereby counter-balancing the effect of ACE/ Ang II and playing critical roles in preventing hypertension and tissue damages ${ }^{24}$.

The protective roles of ACE2 in acute respiratory distress syndrome (ARDS) and acute lung injury have been demonstrated in animal models ${ }^{25-27}$. A recombinant soluble human ACE2 (rhACE2) was recently reported to block SARS-CoV-2 infection in cell culture and human organoids ${ }^{28}$, prompting a phase 2 clinical trial for use of rhACE2 as a treatment for patients with COVID-19 (NCT04335136). Thus, administration of exogenous ACE2 may be

'Division of Molecular Medicine, Boston Children's Hospital, Boston, MA, USA. 2Department of Pediatrics, Harvard Medical School, Boston, MA, USA. ${ }^{3}$ Codex BioSolutions, Inc., Gaithersburg, MD, USA. ${ }^{4}$ Department of Microbiology, Boston University School of Medicine and National Emerging Infectious Diseases Laboratories, Boston, MA, USA. ${ }^{5}$ Center for Virology and Vaccine Research, Beth Israel Deaconess Medical Center, Boston, MA, USA. ${ }^{6}$ Department of Immunology and Microbiology, Scripps Research Institute, Jupiter, FL, USA. ${ }^{凶}$-mail: bchen@crystal.harvard.edu 
Table 1 | Cryo-EM data collection, refinement and validation statistics

\begin{tabular}{|c|c|c|c|c|}
\hline & $\begin{array}{l}\text { SARS-CoV-2 S (no ACE2) } \\
\text { (EMD-22894, PDB 7KJ5) }\end{array}$ & $\begin{array}{l}\text { SARS-CoV-2 S with } 1 \text { ACE2 } \\
\text { (EMD-22891, PDB 7KJ2) }\end{array}$ & $\begin{array}{l}\text { SARS-CoV-2 S with } 2 \text { ACE2 } \\
\text { (EMD-22892, PDB 7KJ3) }\end{array}$ & $\begin{array}{l}\text { SARS-CoV-2 } \\
\text { (EMD-22893, }\end{array}$ \\
\hline \multicolumn{5}{|l|}{ Data collection and processing } \\
\hline Magnification & 105,000 & & & \\
\hline Voltage (kV) & 300 & & & \\
\hline Electron exposure $\left(\mathrm{e}^{-} / \AA^{2}\right)$ & 50.05 & & & \\
\hline Defocus range $(\mu \mathrm{m})$ & $1.6-2.7$ & & & \\
\hline Pixel size $(\AA)$ & 0.825 & & & \\
\hline Symmetry imposed & $\mathrm{Cl}$ & & & \\
\hline Initial particle images (no.) & 407,761 & & & \\
\hline Final particle images (no.) & 32,685 & 15,964 & 13,515 & 26,298 \\
\hline Map resolution $(\AA)$ & 3.6 & 3.6 & 3.7 & 3.4 \\
\hline FSC threshold & 0.143 & 0.143 & 0.143 & 0.143 \\
\hline Map resolution range $(\AA)$ & $2.48-35.51$ & $2.48-36.46$ & $2.82-35.8$ & $2.14-37.87$ \\
\hline \multicolumn{5}{|l|}{ Refinement } \\
\hline Initial model used (PDB ID) & $6 V Y B$ & $6 \mathrm{VYB}, 6 \mathrm{M} 17$ & $6 \mathrm{VYB}, 6 \mathrm{M} 17$ & 6VYB, 6M17 \\
\hline Model resolution $(\AA)$ & 3.5 & 3.6 & 3.5 & 3.4 \\
\hline FSC threshold & 0.5 & 0.5 & 0.5 & 0.5 \\
\hline Map sharpening $B$ factor $\left(\AA^{2}\right)$ & -78.95 & -83.01 & -86.05 & -74.38 \\
\hline \multicolumn{5}{|l|}{ Model composition } \\
\hline Nonhydrogen atoms & 23,562 & 28,560 & 33,643 & 38,776 \\
\hline Protein residues & 2,909 & 3,502 & 4,109 & 4,722 \\
\hline Ligands & 59 & 70 & 80 & 90 \\
\hline \multicolumn{5}{|l|}{$B$ factors $\left(\AA^{2}\right)$} \\
\hline Protein & 46.79 & 57.46 & 65.84 & 185.79 \\
\hline Ligand & 46.01 & 60.58 & 73.29 & 130.45 \\
\hline \multicolumn{5}{|l|}{ R.m.s. deviations } \\
\hline Bond lengths $(\AA)$ & 0.015 & 0.012 & 0.013 & 0.013 \\
\hline Bond angles $\left({ }^{\circ}\right)$ & 1.997 & 1.857 & 1.826 & 1.900 \\
\hline \multicolumn{5}{|l|}{ Validation } \\
\hline MolProbity score & 2.02 & 1.99 & 1.95 & 1.96 \\
\hline Clashscore & 5.44 & 6.69 & 6.29 & 4.77 \\
\hline Poor rotamers (\%) & 2.00 & 1.72 & 1.58 & 2.36 \\
\hline \multicolumn{5}{|l|}{ Ramachandran plot } \\
\hline Favored (\%) & 91.62 & 93.12 & 92.84 & 93.40 \\
\hline Allowed (\%) & 7.95 & 6.38 & 6.46 & 6.09 \\
\hline Disallowed (\%) & 0.42 & 0.50 & 0.69 & 0.52 \\
\hline
\end{tabular}

a promising therapeutic strategy for treating COVID-19, because it could not only block viral spread but also modulate the RAS to prevent organ injury. We therefore set out to design a series of ACE2 variants to enhance their binding affinity for SARS-CoV-2 S protein and their potency in blocking SARS-CoV-2 infection.

\section{Results}

Structures of soluble ACE2 in complex with SARS-CoV-2 S protein trimer. To facilitate design of ACE2-based viral fusion inhibitors, we first determined, by cryo-EM, the structures of a monomeric soluble ACE2 (residues 18-615) in complex with a stabilized soluble SARS-CoV-2 S protein trimer (Extended Data Fig. 1; ref. ${ }^{29}$ ). We prepared the complex by mixing the two proteins because the monomeric ACE2 dissociates from $S$ trimer very rapidly $^{30}$. After three-dimensional (3D) classification (Extended Data
Figs. 2 and 3 and Table 1), we found four distinct classes that represent $S$ trimer with different numbers of ACE2 bound: no ACE2 (in the one-RBD-up conformation); and with one to three ACE2s bound (Fig. 1). Consistent with previous findings with ACE2 binding to SARS-CoV S protein as well as a recent SARS-CoV-2 study ${ }^{31}$, ACE2 interacts with the RBD in its up conformation. While the $\mathrm{N}$-terminal domain of S1 shifts outwards slightly, the S2 portion remains largely unchanged upon ACE2 binding, even when compared with our recently published structure of the full-length $S$ protein in the closed prefusion conformation ${ }^{30}$. The structure of the complex with three ACE2s bound is not symmetrical, as the distances between the $\mathrm{C}$ termini of the three ACE2s (residue Tyr613) are $107 \AA, 109 \AA$ and $120 \AA$, respectively (Extended Data Fig. 4). This distance in the complex with two ACE2s bound is $110 \AA$. These observations suggest that there is a modest degree of freedom for 

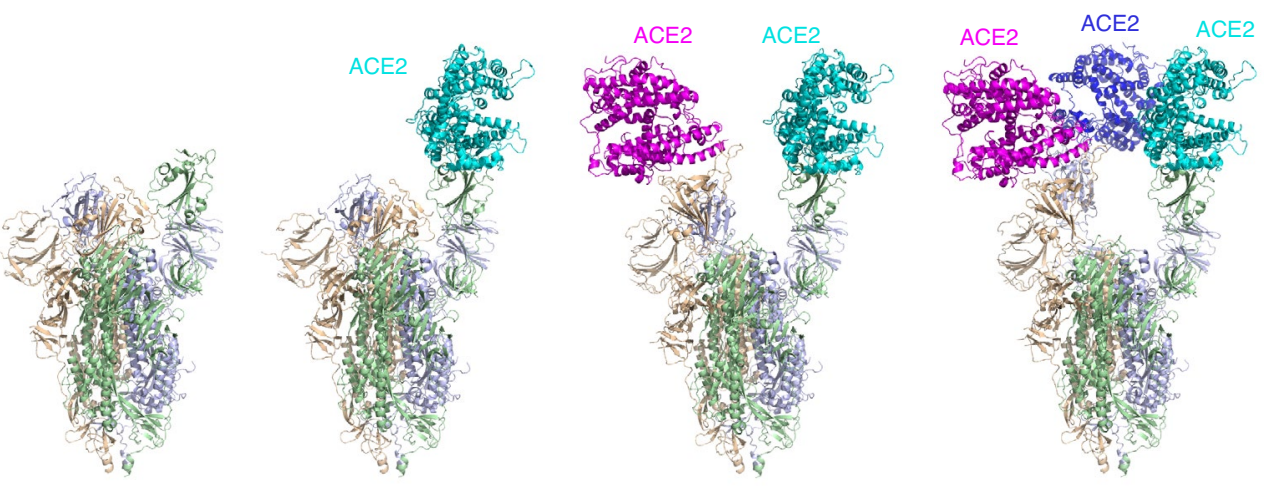

Fig. 1 | Cryo-EM structures of the ACE2-soluble S trimer complexes. Four distinct classes were identified and refined from a sample prepared by mixing monomeric ACE2 and the stabilized soluble SARS-CoV-2 trimer. Left, the structure of the S trimer without ACE2 in a conformation with one RBD up was modeled based on a 3.6- $\AA$-resolution density map. The three protomers are colored in green, blue and wheat, respectively. The structures of the $S$ trimer in complex with one ACE2 (3.6 $)$, two ACE2s (3.7 $\AA$ ) or three ACE2s (3.4 $)$ are shown, with ACE2 colored in dark blue, cyan or magenta.

the up conformation of RBD when ACE2 is bound. All the substrate binding sites of the bound ACE2s face away from the three-fold axis of the $\mathrm{S}$ trimer (Extended Data Fig. 4), incompatible with the structure of the full-length ACE2 dimer in complex with the amino acid transporter $\mathrm{B}^{0} \mathrm{AT} 1$, in which the two active sites of the two protomers are facing each other ${ }^{20}$. If the $\mathrm{B}^{0} \mathrm{AT} 1$-bound ACE2 dimer is indeed the form recognized by SARS-CoV-2, it appears that only one ACE2 protomer in the dimer can bind one RBD in an $\mathrm{S}$ trimer unless there are unexpectedly large structural rearrangements in either ACE2 or S.

Design of ACE2 variants to enhance its binding affinity to SARS-CoV-2 S trimer. Measurement of the binding kinetics of soluble monomeric ACE2 (ACE2 ${ }_{615}$; Fig. 2) to the SARS-CoV-2 S trimer shows a relatively fast dissociation rate $^{30}$, limiting its ability to compete with the membrane-bound ACE2 on the surface of a target cell. We therefore sought to enhance the effective affinity by creating a trimeric form of soluble ACE2. We fused a trimerization foldon tag, derived from bacteriophage T4 fibritin ${ }^{32}$, to the C-terminal end of the ACE2 peptidase domain (residue 615) through an 11-residue flexible linker, a construct we refer to as $\mathrm{ACE} 2_{615}$-foldon (Fig. 2). We have also created another version (ACE2 ${ }_{615}$-LL-foldon) with a slightly longer linker (LL) with 13 residues between ACE2 and the foldon tag to assess its impact on binding. To further strengthen the interaction between ACE2 and the RBD, we introduced mutations guided by high-resolution structures (Extended Data Fig. 5; ref. ${ }^{18}$ ) at three different positions in the ACE2-RBD interface, namely T27, H34 and K353. Substitution with a bulky hydrophobic residue at each of these sites may enhance hydrophobic interactions between the two proteins and slow the dissociation (Extended Data Fig. 5). We designed five mutants, T27Y, T27W, H34W, K353Y and $\mathrm{K} 353 \mathrm{~W}$, in the ACE $2_{615}$-foldon background. Finally, for comparison, we also include two versions of dimeric forms, ACE2 $\mathrm{m}_{615}-\mathrm{Fc}$ and ACE $2_{740}-\mathrm{Fc}$, both fused to an Fc domain of an immunoglobulin $\mathrm{G}$ (Fig. 2a). ACE2m615-Fc contains $\mathrm{H} 374 \mathrm{~N}$ and $\mathrm{H} 378 \mathrm{~N}$ mutations at its peptidase active site and ACE2740-Fc includes the neck domain that mediates dimerization in the full-length ACE2 (ref. ${ }^{20}$ ).

To produce the soluble recombinant ACE2 and its variants, we transfected HEK293 cells with the expression constructs of the monomeric and trimeric forms containing a C-terminal His tag and purified the proteins by Ni-NTA (nitrilotriacetic acid) and gel filtration chromatography. The two dimeric forms were purified by protein $\mathrm{G}$ resin followed by gel filtration chromatography. While the monomeric and dimeric forms of soluble ACE2 were mostly secreted into cell medium, as judged by western blot, the trimeric ACE $2_{615}$-foldon and its mutants were largely retained inside the cells. We therefore purified the secreted monomer and dimers from the cell supernatants and all the trimers from the cell lysates. Most proteins eluted from a size-exclusion column as a major symmetrical peak, regardless of their secretion status (Extended Data Fig. 6). The ACE $2_{740}$-Fc protein containing the dimerizing neck domain appeared to aggregate substantially more than other constructs. The ACE $2_{615}$-foldon K353W mutant aggregated completely, and we therefore did not pursue this construct any further. Only the fractions from the major peak for each construct were pooled and used for subsequent analyses. We have also compared the secreted ACE $2_{615}$-foldon with the form purified from the cells and their biochemical properties are essentially identical (Extended Data Fig. 7).

Binding to SARS-CoV-2 soluble $\mathrm{S}$ trimer. We next measured binding of these recombinant ACE2 constructs to the stabilized soluble $\mathrm{S}$ trimer by bio-layer interferometry (BLI). As shown in Fig. $2 \mathrm{~b}$ and Extended Data Fig. 8, the monomeric ACE2 ${ }_{615}$ had a fast dissociation rate and a $K_{\mathrm{d}}$ of $77 \mathrm{nM}$, consistent with the measurement that we reported recently using surface plasmon resonance $\left(\right.$ ref. $\left.{ }^{30}\right)$. The dimeric ACE2 $\mathrm{m}_{615}$-FC bound slightly more tightly $\left(K_{\mathrm{d}} \sim 22 \mathrm{nM}\right)$. The dimeric $\mathrm{ACE} 2_{740}-\mathrm{Fc}$ also bound more strongly than did the monomer $\left(K_{\mathrm{d}} \sim 12 \mathrm{nM}\right)$, although the dimer formed by the neck domain is not compatible with two ACE2 peptidase domains interacting with two distinct RBDs in a single $\mathrm{S}$ trimer (Extended Data Fig. 4). A possible explanation is that the neck domain-mediated dimerization is not very strong and that the ACE2 peptidase domains are much more flexible than what the full-length ACE2 structure has indicated ${ }^{20}$, particularly in the absence of $\mathrm{B}^{0} \mathrm{AT} 1$. The trimeric $\mathrm{ACE} 2_{615}$-foldon interacted with the $\mathrm{S}$ trimer much more strongly than any of the monomeric or dimeric forms, with a $K_{\mathrm{d}}$ of $1.2 \mathrm{nM}$. ACE $2_{615}$-LL-foldon with a longer linker between ACE2 and foldon showed an additional modest affinity enhancement $\left(K_{\mathrm{d}} \sim 0.62 \mathrm{nM}\right)$. The two interface mutants, ACE2 ${ }_{615}$-foldon-T27W and $\mathrm{ACE} 2_{615}$-foldon-T27Y, bound substantially more tightly than did the trimeric wild-type ACE2, with $K_{\mathrm{d}}$ of $\sim 60$ and $\sim 90 \mathrm{pM}$, respectively. While the $\mathrm{H} 34 \mathrm{~W}$ afforded a slight affinity increase, the K353Y mutation decreased affinity by more than 25 -fold. Overall, these data show that our structure-guided design to increase the affinity of ACE2 to the S trimer, by trimerizing the receptor and by modifying the interface, has indeed been effective.

ACE2 peptidase activity and AT1R activation. We performed two independent assays to determine the enzymatic activity of these ACE2 constructs. First, we directly measured the peptidase activity using a synthetic peptide substrate that releases a free fluorophore upon ACE2 cleavage. In Fig. 3a, concentrations of all the 
a
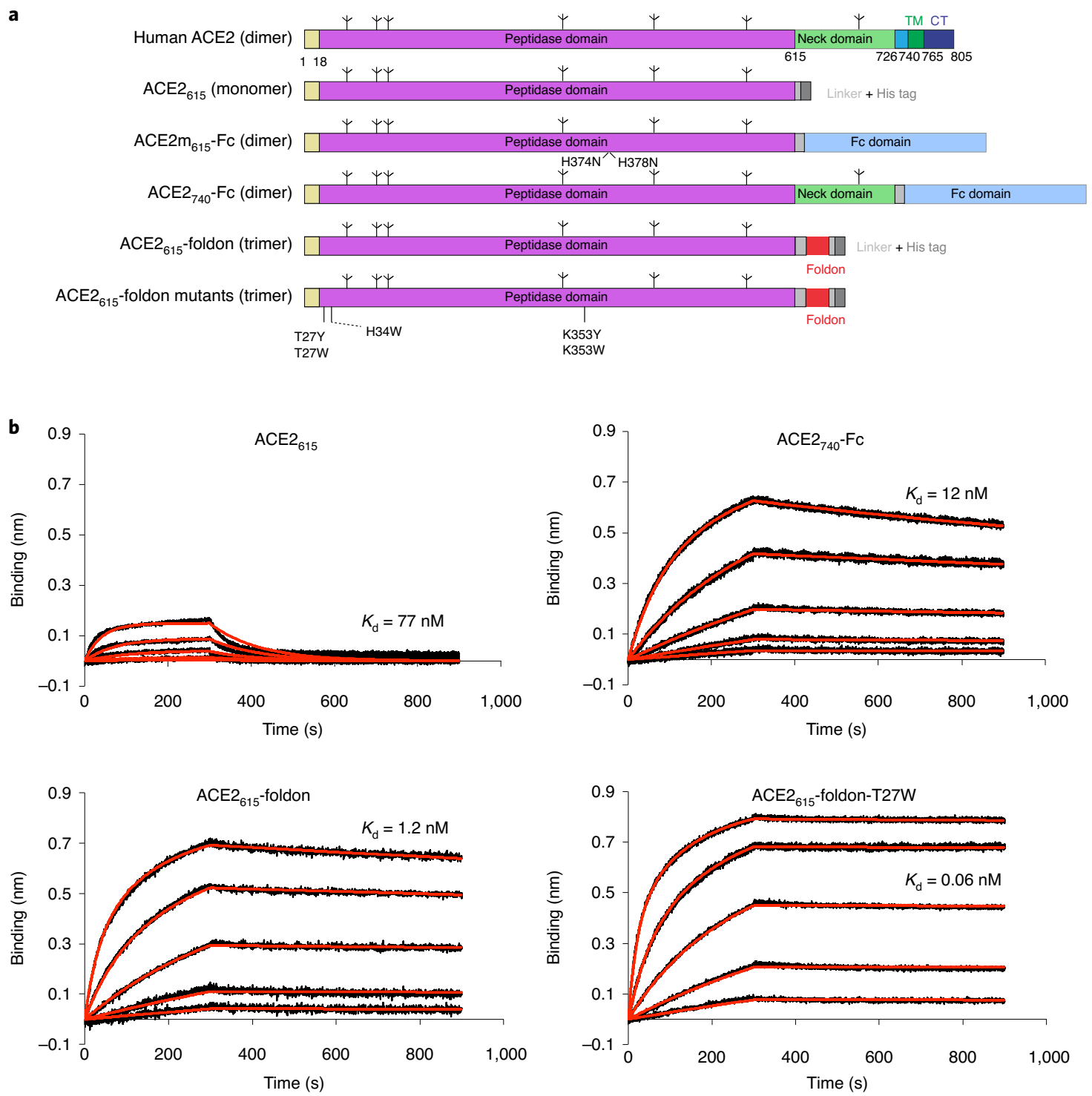

Fig. 2 | Design and characterization of ACE2 variants. a, Schematic representation of the full-length human ACE2. Various segments include: catalytic peptidase domain; neck domain; TM, transmembrane anchor; $\mathrm{CT}$, cytoplasmic tail; tree-like symbols represent glycans. Expression constructs of various forms of ACE2 used in this study: ACE2 ${ }_{615}$, the peptidase domain fused with a C-terminal His tag via a flexible linker; $A C E 2 m_{615}-F_{c}$, an inactive peptidase domain with mutations at the active site ( $\mathrm{H} 374 \mathrm{~N}$ and $\mathrm{H} 378 \mathrm{~N})$ fused to an $\mathrm{Fc}$ fragment of an immunoglobulin $\mathrm{G}$ at the $\mathrm{C}$ terminus; $\mathrm{ACE} 2_{740}-\mathrm{Fc}$, the peptidase and neck domains fused to an Fc fragment at the $\mathrm{C}$ terminus; $\mathrm{ACE} 2_{615}$-foldon, the peptidase domain fused to a trimerization tag-foldon, followed by a C-terminal His tag; ACE2 615 -foldon mutants, single mutations (T27Y, T27W, H34W, K353Y and K353W) were introduced in the context of the ACE2 615 -foldon construct. b, Binding of ACE2 variants to the stabilized soluble $S$ trimer by BLI. The $S$ protein was immobilized to AR2G biosensors, which were dipped into the wells containing ACE2 at various concentrations (1.852-150 nM for ACE2 ${ }_{615}, 0.926-75 \mathrm{nM}$ for $\mathrm{ACE} 2_{740}-\mathrm{FC}$ and $0.617-50 \mathrm{nM}$ for all the ACE2 $2_{615}$-foldon variants). Binding kinetics were evaluated using a 1:1 Langmuir binding model for the monomeric ACE2 615 and a bivalent model for all other oligomeric ACE2s. The sensorgrams are in black and the fits in red. All experiments were repeated at least twice with independent samples and essentially identical results. Binding constants derived from the BLI experiments are summarized in Table 2.

proteins were normalized based on the number of active sites, and the fluorophore release was monitored continuously up to $\sim 40 \mathrm{~min}$. While all the trimeric forms showed essentially the same specific activity, the monomeric ACE2 $2_{615}$ and the dimeric ACE2 $2_{740}-\mathrm{Fc}$ had lower specific activities (Table 2 and Supplementary Table 1). The ACE2 $\mathrm{m}_{615}-\mathrm{Fc}$ was inactive due to the mutations at the active site. Thus, all these ACE2 constructs with the wild-type sequence at the active site retained their wild-type peptidase activity.

To further support this conclusion, we next tested the ability of the ACE2 constructs to block Ang II-induced activation of AT1R. In Fig. 3b, an Ang II peptide was first directly incubated with various
ACE2 proteins and then added to HEK293 cells transfected with an AT1R expression construct. Activation of AT1R was monitored by changes in the intracellular calcium concentration. When the digestion reaction was quenched by EDTA at time 0 as a control, all the mixtures with different ACE2 proteins could efficiently activate AT1R, suggesting that nothing in our protein preparations inhibited Ang II-mediated AT1R activation. In contrast, when the digestion was allowed to proceed for $40 \mathrm{~min}$, all AEC2 constructs except for the inactive ACE2 $\mathrm{m}_{615}$-Fc effectively blocked AT1R activation, presumably by converting Ang II to Ang 1-7, in agreement with the peptidase activity results. 
a
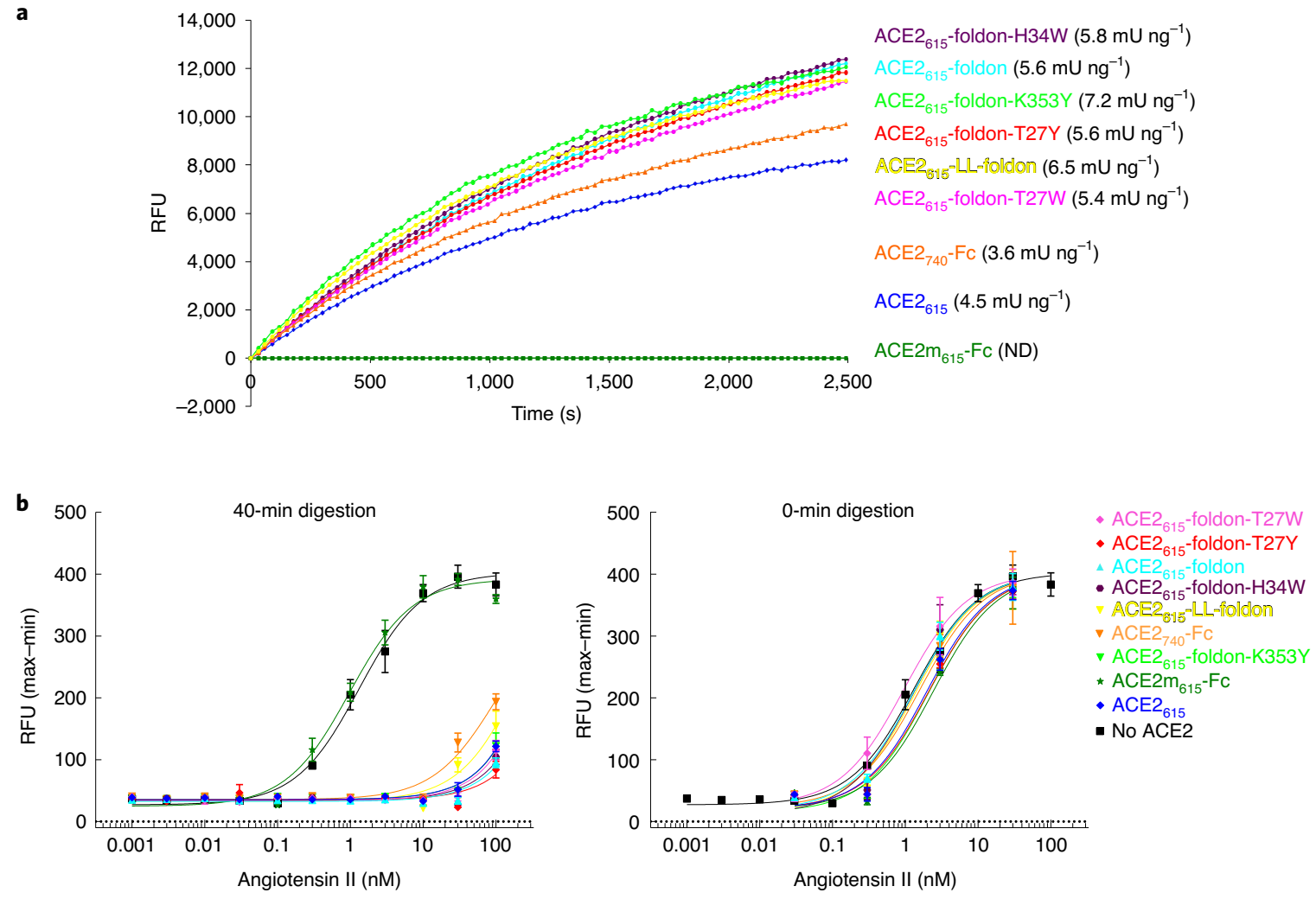

Fig. 3 | ACE2 peptidase activity and negative regulation of AT1R activation. a, Peptidase activity of the ACE2 variants was measured by detecting free fluorophore released from a synthetic peptide substrate in a time course experiment. Calculated specific activities are listed and summarized in Table 2. The experiment has been repeated twice with independent samples and similar results. $\mathbf{b}$. Ang II peptide was treated with various ACE2 variants before addition to the cells expressing AT1R at different concentrations. AT1R activation was quantified by changes in the intracellular calcium concentration. Samples quenched at time 0 were used as controls. The $y$ axis is relative fluorescence units (peak fluorescence intensity - baseline fluorescence intensity). The $\mathrm{EC}_{50}$ values are summarized in Table 2. Data are mean and s.d. for $n=4$ technical replicates; data behind graphs are available as source data. The experiment has been repeated at least three times with independent samples and similar results. RFU, relative fluorescence unit.

Table 2 | Binding affinity, peptidase function and SARS-CoV-2 inhibition potency of ACE2 constructs ${ }^{\mathrm{a}}$

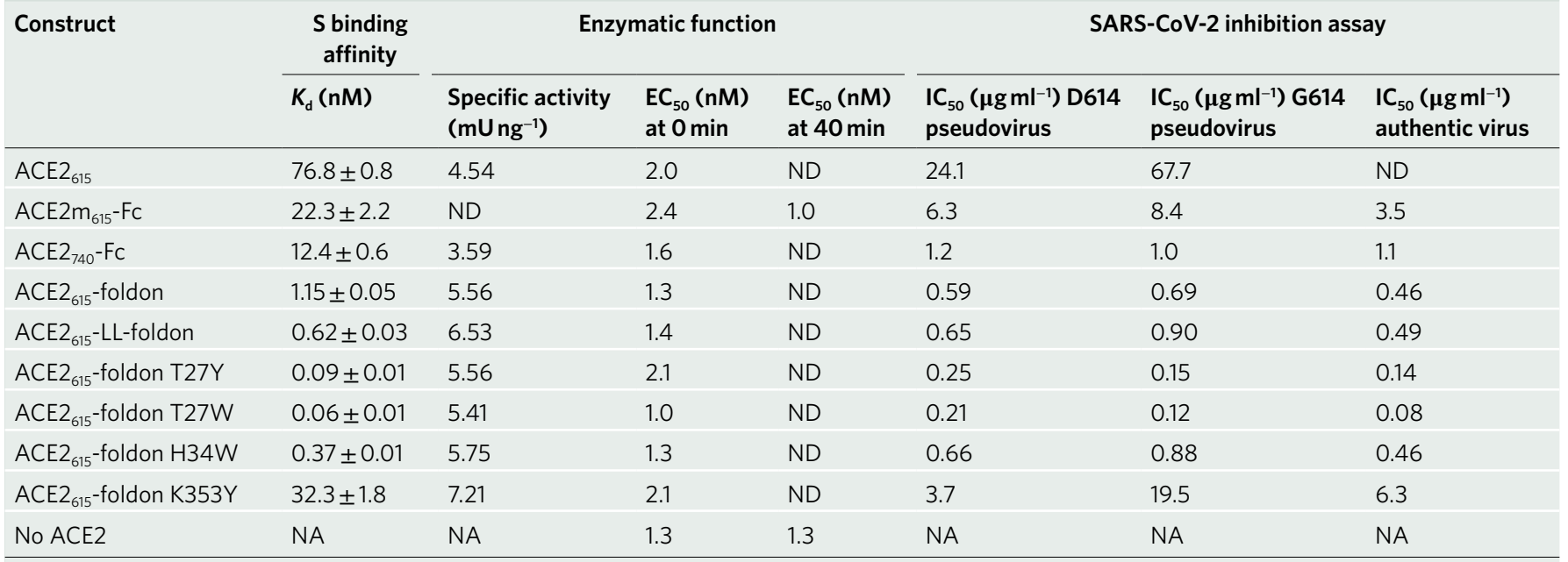

aBinding affinity measurements with SARS-CoV-2 soluble S trimer by BLI shown in Fig. $2 \mathrm{~b}$ and Extended Data Fig. 8 are summarized in column 2. Peptidase activities and measurements for inhibition of AT1R activation (Fig. 3) are listed in columns 3-5. Negative regulation was indicated as activation by Ang II peptide after incubation with different ACE2 constructs for 40 min (half-maximum effective concentration $\left(E_{50}\right)$ at $40 \mathrm{~min}$ ). Samples quenched at time 0 were used as controls, of which the $\mathrm{Ang} / \mathrm{I}$ activations $\left(\mathrm{EC}_{50}\right.$ at 0 min) are summarized in column 4 . Inhibition potency measurements in the assays using pseudoviruses and authentic viruses (Fig. 4) are listed in columns 6-8. ND, not determined; NA, not applicable.

Inhibition of SARS-CoV-2 infectivity in cell culture. We used three different assays to assess the neutralization potency of the ACE2 constructs in blocking SARS-CoV-2 infection. The circulating strain during the early days of the pandemic contained a D614 residue in its $\mathrm{S}$ protein, but it has subsequently been replaced by an emerging strain harboring a G614 substitution ${ }^{33}$. It has been 


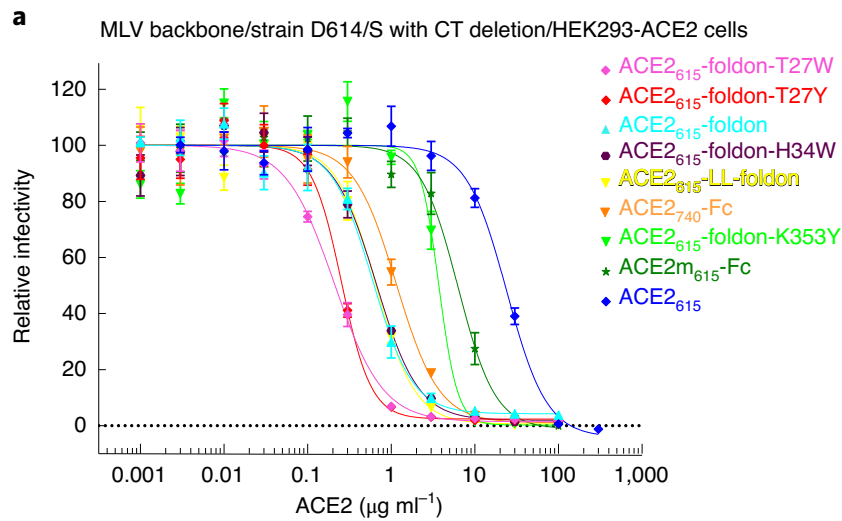

b HIV backbone/strain G614/full-length S/HEK 293-ACE2 cells
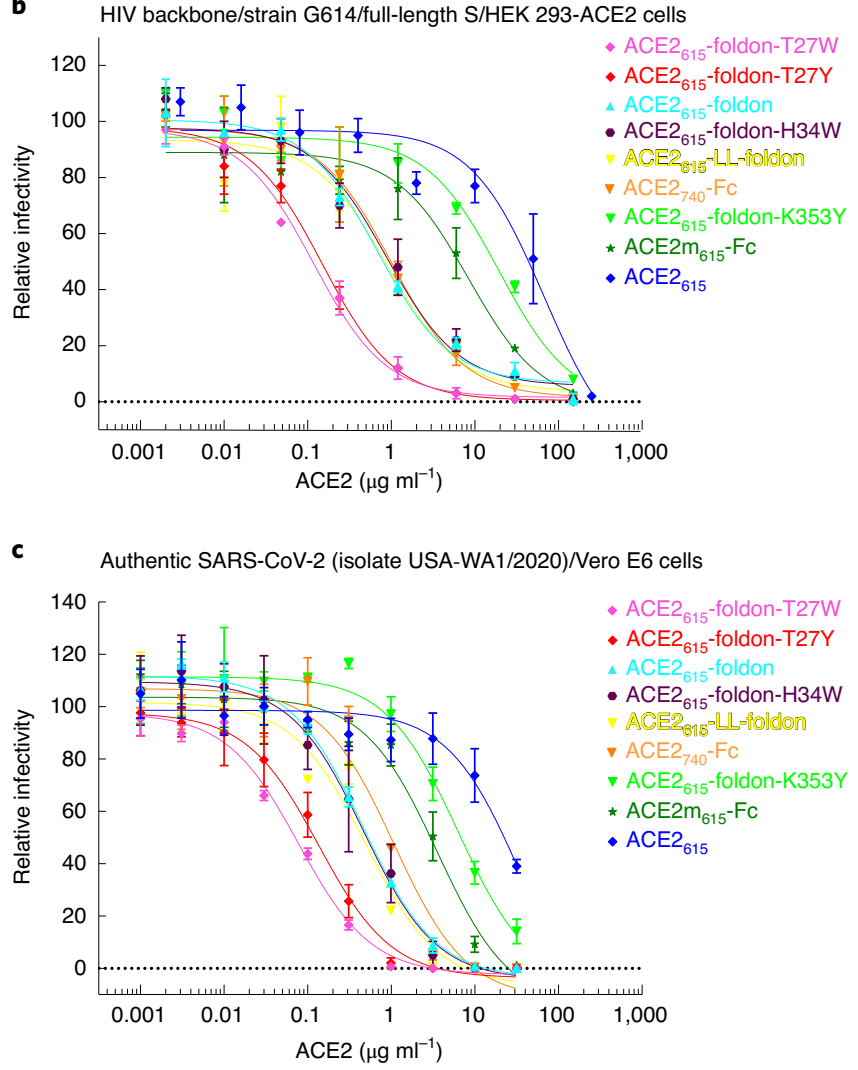

Fig. 4 | Inhibition of SARS-CoV-2 pseudoviruses and authentic viruses by ACE2 variants. a, Serial dilutions of each ACE2 variant were tested for inhibition against an MLV-based pseudotyped virus using a SARS-CoV-2 $S$ construct containing D614 and a CT deletion in a single-round infection of HEK293-ACE2 cells. The experiments were repeated three times with independent samples giving similar results. b, ACE2 variants were tested for inhibition against an HIV-based pseudotyped virus using a full-length SARS-CoV-2 S construct containing G614 in a single-round infection of HEK293-ACE2 cells. The experiments were repeated twice with independent samples giving similar results. c, Serial dilutions of each ACE2 variant were tested for inhibition against an authentic SARS-CoV-2 S virus (isolate USA-WA1/2020) infecting Vero E6 cells. The experiments were repeated three times with similar results. For all panels, data points shown are mean and s.d. for $n=3$ technical replicates. Data behind graphs are available as source data. $I C_{50}$ values derived from curve fitting are listed in Table 2 and Supplementary Table 2.

difficult to generate pseudotyped viruses with the full-length $S$ from the D614 strain $^{34}$. We first used a murine leukemia virus (MLV)-based pseudovirus assay with a D614 S construct lacking 19 residues of the
CT, which incorporates efficiently into pseudoviruses. In Fig. 4a, the monomeric ACE2 ${ }_{615}$ showed the lowest potency with a half-maximal inhibitory concentration $\left(\mathrm{IC}_{50}\right.$ ) value of $24.1 \mu \mathrm{g} \mathrm{ml}^{-1}$. The two dimeric forms, $\mathrm{ACE} 2 \mathrm{~m}_{615}-\mathrm{Fc}$ and $\mathrm{ACE} 2_{740}-\mathrm{Fc}$, and the trimeric mutant $\mathrm{ACE} 2_{615}$-foldon-K353Y had greater potency, with $\mathrm{IC}_{50}$ values ranging from 1.2 to $6.3 \mu \mathrm{g} \mathrm{ml}^{-1}$. The two trimeric forms, ACE $2_{615}$-foldon and ACE2 ${ }_{615}$-LL-foldon, and the trimeric mutant ACE $2{ }_{615}$-foldon-H34W neutralized with even greater potency and an $\mathrm{IC}_{50}$ value around $0.6 \mu \mathrm{g} \mathrm{ml}^{-1}$. The most potent inhibitors were ACE $2_{615}$-foldon-T27W and ACE2 ${ }_{615}$-foldon-T27Y, which had $\mathrm{IC}_{50}$ values of 0.21 and $0.25 \mu \mathrm{g} \mathrm{ml}^{-1}$, respectively. Thus, the neutralization potency of these ACE2 constructs correlates strictly with their binding affinity, suggesting that the interaction between ACE2 and S is the principal determinant of neutralization of the virus pseudotyped with the CT-truncated S (D614). Neutralization by these ACE2 proteins in the human immunodeficiency virus (HIV)-based pseudovirus assay using a full-length $\mathrm{S}$ derived from the G614 circulating strain showed a very similar pattern, with $\mathrm{ACE} 2_{615}$ the weakest and ACE $2_{615}$-foldon-T27W and ACE2 ${ }_{615}$-foldon-T27Y the most potent (Fig. 4b). Furthermore, when they were analyzed by a plaque assay with an authentic SARS-CoV-2 (Fig. 4c), the neutralization pattern was almost identical to that from the MLV-based assay (Table 2 and Supplementary Table 2). The $\mathrm{IC}_{50}$ values for $\mathrm{ACE} 2_{615}$-foldon-T27W and $\mathrm{ACE} 2{ }_{615}$-foldon-T27Y were 0.08 and $0.14 \mu \mathrm{g} \mathrm{ml}^{-1}$, respectively. These results indicate that the engineered ACE2 constructs are very potent agents for blocking SARS-CoV-2 infection in cell culture.

\section{Discussion}

A recombinant human ACE2, named APN01, is currently under evaluation as a treatment for COVID-19 in a phase 2 clinical trial (NCT04335136), primarily based on the favorable results from a previous phase 1 safety and tolerability trial (NCT00886353) in a small number of healthy individuals ${ }^{35}$, as well as on the recent evidence that the protein blocks SARS-CoV-2 infection effectively in vitro ${ }^{28}$. APN01 is a soluble ACE2 construct expressing residues 1-740 and probably dimerizes by the neck domain ${ }^{36}$, similar to ACE $2_{740}-\mathrm{Fc}$ used in our study. We demonstrate here that our best trimeric ACE2 variant, ACE2 ${ }_{615}$-foldon-T27W, has $>200$-fold-higher binding affinity for the soluble SARS-CoV-2 S trimer, and $\sim 5$-foldand $\sim 13$-fold-higher neutralization potency against pseudoviruses and authentic viruses, respectively, than does $\mathrm{ACE} 2_{740}-\mathrm{Fc}$, while its peptidase activity and ability to block AT1R activation remain essentially unchanged.

Using a deep mutagenesis screening approach, a recent study has identified a dimeric ACE2 variant containing multiple mutations, which led to higher affinity binding to the RBD, but also a substantial loss in the catalytic activity (4-8-fold decrease), than the parental construct with the wild-type sequence ${ }^{37}$. One of the mutations from the mutagenesis screening is T27Y, coinciding with our structure-based design. Another study reported a trimeric ACE2 construct with the wild-type sequence ${ }^{38}$, similar to our ACE $2_{615}$-foldon protein. Moreover, de novo protein design based on the ACE2 helix that interacts with the RBD without the catalytic domain has led to picomolar SARS-CoV-2 miniprotein inhibitors ${ }^{39}$. Our approach, however, distinguishes the S protein binding and the peptidase activity, which can be manipulated separately to maximize the therapeutic benefits of an ACE2 construct.

Although the molecular mechanism by which a soluble ACE2 blocks SARS-CoV-2 infection as a decoy receptor is obvious, its protective role against lung injury-a hallmark of severe COVID-19 cases-appears to be more complicated in humans than in animal models. ACE2 knockout mice have more severe ARDS symptoms than do wild-type mice, whereas ACE2 overexpression appears to be protective ${ }^{25}$. Moreover, administration of recombinant ACE2 reduces severity of lung injury in mice caused by respiratory syncytial virus or influenza virus ${ }^{26,27}$. In humans, rhACE2 was well 
tolerated with a short half-life ${ }^{35}$, but its infusion did not appear to ameliorate ARDS at least in a small number of patients ${ }^{40}$. A recent case report described using APN01 to treat a patient with severe COVID-19 with a very encouraging outcome ${ }^{41}$. The ongoing phase 2 clinical trial with expected 200 participants may provide much needed information regarding the therapeutic potential of recombinant ACE2 in the context of COVID-19. Structure-based modifications presented here may help augment therapeutic efficacy while suppressing adverse effects, if any.

The safety in humans of the foldon trimerization tag, derived from the bacteriophage T4 fibritin ${ }^{32}$, has been demonstrated by vaccine trials against HIV-1 and SARS-CoV-2 in clinical settings ${ }^{42,43}$. However, a dose in milligrams per kilogram of body weight of the trimeric ACE2 proteins as a therapeutic is likely much greater than that used as a vaccine (for example, $50-250 \mu \mathrm{g}$ of foldon-stabilized HIV-1 gp140 protein per injection; ref. ${ }^{42}$ ). If the foldon tag induces unacceptable levels of side effects at a high dose in animals or humans, other trimerization domains, such as those in abundant human collagens ${ }^{44}$, can be considered. Further improvements of these ACE2-based therapeutic candidates include modifications to enhance protein stability by introducing additional disulfide bonds (which may reduce the catalytic activity), to modulate peptidase activity by mutating residues in or near the active site and to increase its in vivo residence time in circulation, by strategies such as PEGylation ${ }^{45}$.

The structure of the membrane-bound ACE2 dimer formed by the neck domain is not compatible with a binding mode of two protomers interacting with two RBDs from a single $S$ trimer, as depicted in Extended Data Fig. 4. Much stronger binding of $\mathrm{ACE} 2_{740}-\mathrm{Fc}$ to the $\mathrm{S}$ trimer as well as greater neutralization potency than those of monomeric $\mathrm{ACE} 2_{615}$ and even dimeric ACE2 $\mathrm{m}_{615}$-Fc clearly indicate avidity, suggesting that the ectodomain of either ACE2 or SARS-CoV-2 S protein has much greater flexibility than the cryo-EM structures imply ${ }^{20,30,46,47}$. If the multivalency of the trimeric $S$ protein on the surface of virion and the dimeric ACE2 on the host cells indeed plays an important role during viral attachment, the binding affinity for the virus to latch on to the target cells would be much stronger than the values measured using monomeric ACE2 (ref. ${ }^{46}$ ). This multivalency may help explain the unexpected transmission efficiency of SARS-CoV-2 leading to a pandemic on a surprising scale and raise the hurdle for antivirals to effectively compete with ACE2 for S binding. Trimeric ACE2 variants exerting even greater avidity than the dimeric form on the host cells may have a competitive edge over other RBD-targeting inhibitors, such as monoclonal antibodies, with similar binding affinity.

\section{Online content}

Any methods, additional references, Nature Research reporting summaries, source data, extended data, supplementary information, acknowledgements, peer review information; details of author contributions and competing interests; and statements of data and code availability are available at https://doi.org/10.1038/ s41594-020-00549-3.

Received: 11 October 2020; Accepted: 16 December 2020; Published online: 11 January 2021

\section{References}

1. Duan, K. et al. Effectiveness of convalescent plasma therapy in severe COVID-19 patients. Proc. Natl Acad. Sci. USA 117, 9490-9496 (2020).

2. Bloch, E. M. et al. Deployment of convalescent plasma for the prevention and treatment of COVID-19. J. Clin. Invest. 130, 2757-2765 (2020).

3. Shen, C. et al. Treatment of 5 critically ill patients with COVID-19 with convalescent plasma. JAMA 323, 1582-1589 (2020).

4. Wec, A. Z. et al. Broad neutralization of SARS-related viruses by human monoclonal antibodies. Science 369, 731-736 (2020).
5. Shi, R. et al. A human neutralizing antibody targets the receptor binding site of SARS-CoV-2. Nature 584, 120-124 (2020).

6. Chi, X. et al. A neutralizing human antibody binds to the $\mathrm{N}$-terminal domain of the spike protein of SARS-CoV-2. Science 369, 650-655 (2020).

7. Wu, Y. et al. A noncompeting pair of human neutralizing antibodies block COVID-19 virus binding to its receptor ACE2. Science 368, 1274-1278 (2020)

8. Xia, S. et al. Inhibition of SARS-CoV-2 (previously 2019-nCoV) infection by a highly potent pan-coronavirus fusion inhibitor targeting its spike protein that harbors a high capacity to mediate membrane fusion. Cell Res. 30, 343-355 (2020)

9. Xia, S. et al. Fusion mechanism of 2019-nCoV and fusion inhibitors targeting HR1 domain in spike protein. Cell Mol. Immunol. 17, 765-767 (2020).

10. Sanders, J. M., Monogue, M. L., Jodlowski, T. Z. \& Cutrell, J. B. Pharmacologic treatments for coronavirus disease 2019 (COVID-19): a review. JAMA 323, 1824-1836 (2020).

11. $\mathrm{Wu}, \mathrm{R}$. et al. An update on current therapeutic drugs treating COVID-19. Curr. Pharmacol. Rep. https://doi.org/10.1007/s40495-02000216-7 (2020).

12. Boulware, D. R. et al. A randomized trial of hydroxychloroquine as postexposure prophylaxis for Covid-19. N. Engl. J. Med. 383, 517-525 (2020).

13. Jin, Z. et al. Structure of $\mathrm{M}^{\text {pro }}$ from SARS-CoV-2 and discovery of its inhibitors. Nature 582, 289-293 (2020).

14. Gao, Y. et al. Structure of the RNA-dependent RNA polymerase from COVID-19 virus. Science 368, 779-782 (2020).

15. Polak, S. B., Van Gool, I. C., Cohen, D., von der Thüsen, J. H. \& van Paassen, J. A systematic review of pathological findings in COVID-19: a pathophysiological timeline and possible mechanisms of disease progression. Mod. Pathol. 33, 2128-2138 (2020).

16. Zhou, P. et al. A pneumonia outbreak associated with a new coronavirus of probable bat origin. Nature 579, 270-273 (2020).

17. Hoffmann, M. et al. SARS-CoV-2 cell entry depends on ACE2 and TMPRSS2 and is blocked by a clinically proven protease inhibitor. Cell 181, 271-280 (2020)

18. Lan, J. et al. Structure of the SARS-CoV-2 spike receptor-binding domain bound to the ACE2 receptor. Nature 581, 215-220 (2020).

19. Shang, J. et al. Structural basis of receptor recognition by SARS-CoV-2 Nature 581, 221-224 (2020).

20. Yan, R. et al. Structural basis for the recognition of SARS-CoV-2 by full-length human ACE2. Science 367, 1444-1448 (2020).

21. Tikellis, C., Bernardi, S. \& Burns, W. C. Angiotensin-converting enzyme 2 is a key modulator of the renin-angiotensin system in cardiovascular and renal disease. Curr. Opin. Nephrol. Hypertens. 20, 62-68 (2011).

22. Clarke, N. E. \& Turner, A. J. Angiotensin-converting enzyme 2: the first decade. Int J. Hypertens. 2012, 307315 (2012).

23. Dasgupta, C. \& Zhang, L. Angiotensin II receptors and drug discovery in cardiovascular disease. Drug Disco. Today 16, 22-34 (2011).

24. Hemnes, A. R. et al. A potential therapeutic role for angiotensin-converting enzyme 2 in human pulmonary arterial hypertension. Eur. Respir. J. 51, 1702638 (2018).

25. Imai, Y. et al. Angiotensin-converting enzyme 2 protects from severe acute lung failure. Nature 436, 112-116 (2005).

26. $\mathrm{Gu}, \mathrm{H}$. et al. Angiotensin-converting enzyme 2 inhibits lung injury induced by respiratory syncytial virus. Sci. Rep. 6, 19840 (2016).

27. Zou, Z. et al. Angiotensin-converting enzyme 2 protects from lethal avian influenza A H5N1 infections. Nat. Commun. 5, 3594 (2014).

28. Monteil, V. et al. Inhibition of SARS-CoV-2 infections in engineered human tissues using clinical-grade soluble human ACE2. Cell 181, 905-913.e7 (2020).

29. Kirchdoerfer, R. N. et al. Stabilized coronavirus spikes are resistant to conformational changes induced by receptor recognition or proteolysis. Sci. Rep. 8, 15701 (2018)

30. Cai, Y. et al. Distinct conformational states of SARS-CoV-2 spike protein. Science 369, 1586-1592 (2020).

31. Zhou, T. et al. Cryo-EM structures of SARS-CoV-2 spike without and with ACE2 reveal a $\mathrm{pH}$-dependent switch to mediate endosomal positioning of receptor-binding domains. Cell Host Microbe 28, 867-879.e5 (2020)

32. Meier, S., Guthe, S., Kiefhaber, T. \& Grzesiek, S. Foldon, the natural trimerization domain of $\mathrm{T} 4$ fibritin, dissociates into a monomeric A-state form containing a stable $\beta$-hairpin: atomic details of trimer dissociation and local $\beta$-hairpin stability from residual dipolar couplings. J. Mol. Biol. 344 , 1051-1069 (2004)

33. Korber, B. et al. Tracking changes in SARS-CoV-2 spike: evidence that D614G increases infectivity of the COVID-19 virus. Cell 182, 812-827.e19 (2020).

34. Johnson, M. C. et al. Optimized pseudotyping conditions for the SARS-COV-2 spike glycoprotein. J. Virol. 94, https://doi.org/10.1128/ JVI.01062-20 (2020) 
35. Haschke, M. et al. Pharmacokinetics and pharmacodynamics of recombinant human angiotensin-converting enzyme 2 in healthy human subjects. Clin. Pharmacokinet. 52, 783-792 (2013).

36. Poglitsch, M. et al. Recombinant expression and characterization of human and murine ACE2: species-specific activation of the alternative reninangiotensin-system. Int. J. Hypertens. 2012, 428950 (2012).

37. Chan, K. K. et al. Engineering human ACE2 to optimize binding to the spike protein of SARS coronavirus 2. Science 369, 1261-1265 (2020).

38. Guo, L. et al. Engineered trimeric ACE2 binds viral spike protein and locks it in "Three-up" conformation to potently inhibit SARS-CoV-2 infection. Cell Res. 31, 98-100 (2020)

39. Cao, L. et al. De novo design of picomolar SARS-CoV-2 miniprotein inhibitors. Science 370, 426-431 (2020).

40. Khan, A. et al. A pilot clinical trial of recombinant human angiotensinconverting enzyme 2 in acute respiratory distress syndrome. Crit. Care 21, 234 (2017).

41. Zoufaly, A. et al. Human recombinant soluble ACE2 in severe COVID-19. Lancet Respir. Med. https://doi.org/10.1016/S2213-2600(20)30418-5 (2020).
42. Barouch, D. H. et al. Evaluation of a mosaic HIV-1 vaccine in a multicentre, randomised, double-blind, placebo-controlled, phase 1/2a clinical trial (APPROACH) and in rhesus monkeys (NHP 13-19). Lancet 392, 232-243 (2018).

43. Mulligan, M. J. et al. Phase $1 / 2$ study of COVID-19 RNA vaccine BNT162b1 in adults. Nature 586, 589-593 (2020).

44. Sharma, U. et al. Structural basis of homo- and heterotrimerization of collagen I. Nat. Commun. 8, 14671 (2017).

45. Jevsevar, S., Kunstelj, M. \& Porekar, V. G. PEGylation of therapeutic proteins. Biotechnol. J. 5, 113-128 (2010).

46. Wrapp, D. et al. Cryo-EM structure of the 2019-nCoV spike in the prefusion conformation. Science 367, 1260-1263 (2020).

47. Walls, A. C. et al. Structure, function and antigenicity of the SARS-CoV-2 spike glycoprotein. Cell 181, 281-292 (2020).

Publisher's note Springer Nature remains neutral with regard to jurisdictional claims in published maps and institutional affiliations.

(C) The Author(s), under exclusive licence to Springer Nature America, Inc. 2021 


\section{Methods}

Cell lines. HEK293T cells were purchased from ATCC; Expi293F from Thermo Fisher Scientific. Mycoplasma contamination has been routinely tested for in cell cultures in our laboratory.

Protein expression and purification. A synthetic gene encoding a human ACE2 fragment (residues 1-615) fused with a C-terminal 6xHis tag was generated by GenScript and cloned into pCMV-IRES-puro expression vector (Codex BioSolutions) to create the construct pACE $2_{615}$. To construct a trimeric ACE2 variant, a DNA fragment encoding a foldon trimerization tag was inserted between the ACE2 fragment and the His tag by restriction digestion and DNA ligation to give the plasmid pACE2 ${ }_{615}$-foldon. Site-specific mutations, guided by high-resolution crystal structures (Extended Data Fig. 5), were introduced to the ACE2 ${ }_{615}$-foldon construct by PCR following standard protocols of site-directed mutagenesis. All the ACE2 variants were expressed in HEK293F cells by transient transfection using Opti-MEM (Gibco-Thermo Fisher Scientific). After incubation for $4 \mathrm{~d}$ at $37^{\circ} \mathrm{C}$ with $5.5 \% \mathrm{CO}_{2}$, the transfected cells were collected by centrifugation at $2,524 \mathrm{~g}$ for $30 \mathrm{~min}$.

For the monomeric ACE ${ }_{615}$ protein, the cell supernatant was collected by centrifugation and loaded onto a column packed with Ni-NTA agarose beads (Qiagen). The column was washed with a buffer containing $20 \mathrm{mM}$ Tris-HCl, $\mathrm{pH}$ 7.5 , and $300 \mathrm{mM} \mathrm{NaCl}$. The protein was eluted using a buffer containing $100 \mathrm{mM}$ imidazole, and further purified by gel filtration chromatography on a Superdex 200 Increase 10/300 GL column (GE Healthcare).

To purify the dimeric $\mathrm{ACE} 2_{615}-\mathrm{Fc}$ and $\mathrm{ACE} 2_{740}-\mathrm{Fc}$ proteins, the cell supernatant was collected and loaded onto a column packed with GammaBind Plus Sepharose beads (GE Healthcare). The column was washed with PBS. The protein was eluted using $100 \mathrm{mM}$ glycine ( $\mathrm{pH} 2.5$ ) and neutralized immediately with $2 \mathrm{M}$ Tris-HCl ( $\mathrm{pH}$ 8.0). The eluted protein was further purified by gel filtration chromatography on a Superdex 200 Increase 10/300 GL column.

For all the ACE $2_{615}$-foldon variants, which were not secreted efficiently, the cell pellet was resuspended in the lysis buffer $(20 \mathrm{mM}$ Tris- $\mathrm{HCl}, \mathrm{pH} 7.5,300 \mathrm{mM} \mathrm{NaCl}$, $1 \% \mathrm{NP} 40,20 \mathrm{mM}$ imidazole) and rocked gently for $1 \mathrm{~h}$ at $4^{\circ} \mathrm{C}$, followed by spinning at $17,554 \mathrm{~g}$ for $30 \mathrm{~min}$ to remove cell debris. The supernatant was loaded onto a column packed with Ni-NTA agarose beads (Qiagen). The column was washed with a buffer containing $20 \mathrm{mM}$ Tris- $\mathrm{HCl}, \mathrm{pH} 7.5,300 \mathrm{mM} \mathrm{NaCl}$ and $50 \mathrm{mM}$ imidazole and the protein was eluted using a buffer containing $20 \mathrm{mM}$ Tris- $\mathrm{HCl}, \mathrm{pH} 7.5$, $300 \mathrm{mM} \mathrm{NaCl}$ and $300 \mathrm{mM}$ imidazole. The eluted protein was further purified by gel filtration chromatography on a Superdex 200 Increase 10/300 GL column.

To produce a stabilized ectodomain of SARS-CoV-2 S trimer protein, a synthetic gene (kindly provided by Dr. Dan Barouch), encoding residues 1-1208 with the furin cleavage site (residues 682-685) replaced by a 'GGSG' sequence, residues K986 and V987 substituted by prolines and addition of a foldon trimerization tag followed by a C-terminal $6 x$ His tag, was cloned into the vector pCMV-IRES-puro. The expression construct was transiently transfected in HEK293T cells using polyethylenimine (Polysciences). Protein was purified from cell supernatants using Ni-NTA resin (Qiagen), and the eluted fractions containing $\mathrm{S}$ protein were pooled, concentrated and further purified by gel filtration chromatography on a Superose 6 column (GE Healthcare)

Cryo-EM sample preparation and data collection. To prepare cryo grids, $3.5 \mu \mathrm{l}$ of the freshly prepared mixture of the soluble $\mathrm{S} \mathrm{trimer}$ and monomeric ACE2 (1:3 molar ratio) at $\sim 1 \mathrm{mg} \mathrm{ml}^{-1}$ was applied to a 1.2/1.3 Quantifoil grid (Quantifoil Micro Tools), which had been glow discharged with a PELCO easiGlow Glow Discharge Cleaning system (Ted Pella) for $60 \mathrm{~s}$ at $15 \mathrm{~mA}$. Grids were immediately plunge-frozen in liquid ethane using a Vitrobot Mark IV (Thermo Fisher Scientific), and excess protein was blotted away using grade- 595 filter paper (Ted Pella) with a blotting time of $4 \mathrm{~s}$ and a blotting force of -12 at $4{ }^{\circ} \mathrm{C}$ in $100 \%$ humidity. The grids were first screened for ice thickness and particle distribution using a Talos Arctica transmission electron microscope (Thermo Fisher Scientific), operated at $200 \mathrm{keV}$ and equipped with a K3 direct electron detector (Gatan), at the Harvard Cryo-EM Center for Structural Biology. For data collection, images were acquired with selected grids using a Titan Krios transmission electron microscope (Thermo Fisher Scientific) operated at $300 \mathrm{keV}$ with a BioQuantum GIF/K3 direct electron detector. Automated data collection was carried out using SerialEM version 65 at a nominal magnification of $\times 105,000$ and the $\mathrm{K} 3$ detector in counting mode (calibrated pixel size, $0.825 \AA$ ) at an exposure rate of $\sim 14.8$ electrons per physical pixel per second. Each movie had a total accumulated electron exposure of $50 \mathrm{e}^{-} / \AA^{2}$ fractionated in 50 frames of $50 \mathrm{~ms}$. Datasets were acquired using a defocus range of $1.5-2.6 \mu \mathrm{m}$.

Image processing, 3D reconstructions and model building. Drift correction for cryo-EM images was performed using MotionCor2 (ref. ${ }^{48}$ ), and contrast transfer function (CTF) was estimated by CTFFIND4 (ref. ${ }^{49}$ ) using motion-corrected sums without dose-weighting. Motion-corrected sums with dose-weighting were used for all image processing. $\mathrm{CrYOLO}^{50}$ was used for particle picking, and RELION3.0.8 (ref. ${ }^{51}$ ) was used for two-dimensional (2D) classification, 3D classification and refinement. A total of 407,761 particles were extracted from 4,292 images. The selected particles were subjected to $2 \mathrm{D}$ classification, giving a total of 261,799 good particles. A low-resolution negative-stain reconstruction of the sample was low-pass-filtered to $40 \AA$ and used as an initial model for
3D classification in $C 1$ symmetry. One class containing 32,685 particles that appeared to represent the free $\mathrm{S}$ trimer with no ACE bound was further refined in $C 1$ symmetry, giving a reconstruction at $3.6-\AA \AA$ resolution. Another major class with $\sim 49 \%$ of the selected particles showing density for ACE2 was refined in $C 1$ symmetry and subsequently subjected to CTF refinement, Bayesian polishing and particle subtraction by masking out the ACE2-RBD density, followed by $3 \mathrm{D}$ classification without alignment in six classes. Whole particles were re-extracted based on the six classes from the masked local classification and refined further, revealing different stoichiometry for ACE2 binding (one ACE2 per $S$ trimer, two ACE2s per $S$ trimer, and three ACE2s per $S$ trimer). The three best maps representing each type of complex were chosen and further refined in $C 1$ symmetry after CTF refinement and Bayesian polishing, leading to one reconstruction of the complex with one ACE2 bound at 3.6-A resolution from 15,964 particles; another reconstruction of the complex with two ACE2s bound at $3.7-\AA \AA$ resolution from 13,515 particles; and a third reconstruction of the complex with three ACE2s bound at 3.4- $\AA$ resolution from 26,298 particles. Reported resolutions are based on the gold-standard Fourier shell correlation (FSC) using the 0.143 criterion. All density maps were corrected from the modulation transfer function of the $\mathrm{K} 3$ detector and then sharpened by applying a temperature factor that was estimated using post-processing in RELION. Local resolution was determined using RELION with half-reconstructions as input maps.

The initial templates for model building used the stabilized SARS-CoV-2 S ectodomain trimer structure (PDB 6VYB) and ACE2 from the ACE2-B0AT1 complex structure (PDB 6M17). Several rounds of manual building were performed in $\operatorname{Coot}^{52}$. Iteratively, refinement was performed in both Phenix ${ }^{53}$ (real space refinement) and $\mathrm{ISOLDE}^{54}$, and the Phenix refinement strategy included rigid body fit, minimization_global, local_grid_search and adp, with rotamer, Ramachandran and reference-model restraints, using PDB 6VYB and PDB 6M17 as the reference model. The refinement statistics are summarized in Table 1. Structural biology applications used in this project were compiled and configured by SBGrid ${ }^{55}$.

Binding assay by BLI. Binding of ACE2 variants to the soluble S trimer was measured using an Octet RED384 system (ForteBio). Each ACE2 protein was diluted using the running buffer (PBS, $0.005 \%$ Tween $20,0.25 \mathrm{mg} \mathrm{ml}^{-1} \mathrm{BSA}$ ) and transferred to a 96-well plate. The soluble S protein was immobilized to Amine Reactive 2nd Generation (AR2G) biosensors (ForteBio), following a protocol recommended by the manufacturer. After equilibrating in the running buffer for $5 \mathrm{~min}$, the sensors with immobilized S protein were dipped in the wells containing the ACE2 protein at various concentrations $\left(1.852-150 \mathrm{nM}\right.$ for ACE2 ${ }_{615} ; 0.926-$ $75 \mathrm{nM}$ for ACE2 $\mathrm{m}_{615}-\mathrm{Fc}$ and $\mathrm{ACE} 2_{740}-\mathrm{Fc} ; 0.617-50 \mathrm{nM}$ for all the ACE2 $2_{61}$-foldon variants) for $5 \mathrm{~min}$ to measure the association rate. The sensors were then dipped in the running buffer for $10 \mathrm{~min}$ to determine the dissociation rate. Control sensors with no $\mathrm{S}$ protein were also dipped in the ACE2 solutions and the running buffer as references. Recorded sensorgrams with background subtracted from the references were analyzed using the software Octet Data Analysis HT version 11.1 (ForteBio). The curves for monomeric ACE2 were fit to a 1:1 binding model, while those for the oligomeric ACE2 variants were fit to a bivalent binding model.

ACE2 peptidase activity assay. The catalytic activity of the ACE2 variants was measured by detecting a free fluorophore 7-methoxycoumarin-4-acetic acid (MCA) released from a synthetic peptide substrate, using an ACE2 activity kit (BioVision). The ACE2 ${ }_{615}$ and ACE2 ${ }_{615}$-foldon variants were diluted to $0.25 \mu \mathrm{g} \mathrm{ml}^{-1}$ using the assay buffer from the kit. The ACE2 $\mathrm{m}_{615}-\mathrm{Fc}$ and $\mathrm{ACE} 2_{740}-\mathrm{Fc}$ proteins were diluted to 0.38 and $0.30 \mu \mathrm{g} \mathrm{ml}^{-1}$, respectively, to keep the same number of the active sites as other ACE2 variants. Then, $50 \mu$ l of diluted protein was set in the 96-well plate. Immediately before recording fluorescence signals, $50 \mu \mathrm{l}$ of substrate diluted in the assay buffer, following a protocol recommended by the manufacturer, was added to each well. Fluorescence signals were recorded in a kinetic mode by a Flexstation 3 Multi Mode Microplate Reader (Molecular Devices). The specific activity was calculated as the amount of the released fluorophore divided by the reaction time and the amount of the ACE2 protein using the data within the initial linear phase, as described in the protocol provided by the manufacturer. To determine the initial linear phase, fluorescence signals were recorded with 1.25 , 0.25 and $0.125 \mu \mathrm{g}$ of $\mathrm{ACE} 2_{615}$ protein, respectively, reaching maximum after the substrates were completely cleaved. Data from the first 2 min within the linear phase with signals less than $10 \%$ of the maximum were used for the calculation. The amount of released MCA was derived from the increase of the fluorescence signal divided by the slope of the MCA standard curve.

Inhibition of Ang II-induced AT1R activation. To treat the Ang II peptide with each ACE2 variant, $2 \mu \mathrm{l}$ of ACE2 protein at $0.5 \mathrm{mg} \mathrm{ml}^{-1}$ was added to $198 \mu \mathrm{l}$ of an assay buffer ( $1 \times \mathrm{PBS}, 40 \mathrm{mM}$ Tris- $\left.\mathrm{HCl}, \mathrm{pH} 6.8,20 \mu \mathrm{M} \mathrm{ZnCl}_{2}\right)$ containing $65 \mu \mathrm{M}$ Ang II peptide. The reactions were incubated at $37^{\circ} \mathrm{C}$ for $40 \mathrm{~min}$, and then quenched by addition of $50 \mu \mathrm{l}$ of $0.5 \mathrm{M}$ EDTA. The final concentration of Ang II peptide was $52 \mu \mathrm{M}$. As a time 0 control, $198 \mu \mathrm{l}$ of the assay buffer containing $65 \mu \mathrm{M}$ Ang II was incubated with EDTA at $37^{\circ} \mathrm{C}$ first, followed by addition of $2 \mu \mathrm{l}$ of each ACE2 protein $\left(0.5 \mathrm{mg} \mathrm{ml}^{-1}\right)$.

Changes in the intracellular calcium concentration in AT1R-expressing cells when induced by Ang II peptide were measured to monitor the activation of the 
receptor. Briefly, HEK293 cells were transfected with pCMV-AT1R-IRES-Puro gene using Lipofectamine 3000 reagent (Thermo Fisher Scientifics). At approximately $24 \mathrm{~h}$ post-transfection, the cells were transferred into a 384-well black-clear plate at a density of $1.2 \times 10^{4}$ cells per well in $20 \mu \mathrm{l}$ of culture medium. On day 4, $20 \mu \mathrm{l}$ of $1 \times$ Non-Wash Calcium Dye solution (CB-80500-301, Codex BioSolutions) was added into each well. The cell plate was incubated at $37^{\circ} \mathrm{C}$ in a $\mathrm{CO}_{2}$ incubator for $1 \mathrm{~h}$. The pretreated ligands (Ang II peptide) at various concentrations $(0.005-500 \mathrm{nM})$ were prepared in $1 \times$ HBSS (Hank's balanced salt solution) with $20 \mathrm{mM}$ HEPES (pH 7.46). Fluorescence intensity in each well was recorded on an FDSS 7000 (Hamamatsu Corporation) at the rate of 1 image per second (excitation $480 \mathrm{nM}$ and emission $540 \mathrm{nM}$ ) and the baseline of each well was also recorded for $10 \mathrm{~s}$. After the online addition of $10 \mu \mathrm{l}$ of the prepared ligands (final concentration of $0.001-100 \mathrm{nM}$ ), the fluorescence intensity of each well was recorded at the rate of 1 image per second for an additional $170 \mathrm{~s}$.

MLV-based pseudovirus assay. MLV particles (all plasmids of the MLV components were kindly provided by Dr. Gary Whittaker at Cornell University and Drs. Catherine Chen and Wei Zheng at the National Center for Advancing Translational Sciences, National Institutes of Health (NIH)), pseudotyped with a SARS-CoV-2 S protein construct, were generated in HEK293T cells, following a protocol described previously for SARS-CoV ${ }^{56,57}$. To enhance incorporation, the C-terminal 19 residues in the cytoplasmic tail of the SARS-CoV-2 S protein containing D614 were deleted. To prepare for infection, $7.5 \times 10^{3} \mathrm{Expi2} 23 \mathrm{~F}$ cells, stably transfected with a full-length human ACE2 expression construct, in $15 \mu \mathrm{l}$ of culture medium were plated into a 384-well white-clear plate coated with poly-D-Lysine to enhance cell attachment. On day $2,12.5 \mu \mathrm{l}$ of SARS-CoV-2 MLV pseudoviruses were mixed with $5 \mu \mathrm{l}$ of each ACE2 variant at different concentrations $\left(0.001-300 \mu \mathrm{g} \mathrm{ml} l^{-1}\right)$ and incubated at $37^{\circ} \mathrm{C}$ for $1 \mathrm{~h}$. After the medium in each well containing the cells was removed, $17.5 \mu \mathrm{l}$ of each ACE2-virus mixture was added. The plate was centrifuged at $54 \mathrm{~g}$ for $15 \mathrm{~min}$ at $4^{\circ} \mathrm{C}$ and an additional $7.5 \mu \mathrm{l}$ of culture medium was then added. The total final volume in each well was $25 \mu l$. The cells were then incubated at $37^{\circ} \mathrm{C}$ for $42 \mathrm{~h}$. Luciferase activities were measured with Firefly Luciferase Assay Kit (CB-80552-010, Codex BioSolutions). $\mathrm{IC}_{50}$ values were calculated based on curve fitting in GraphPad Prism.

HIV-based pseudovirus assay. Neutralization of HIV-based pseudovirus containing a full-length SARS-CoV-2 S protein was measured using a single-round infection assay in HEK293T/ACE2 target cells. Pseudotyped virus particles were produced in 293T/17 cells (ATCC) by cotransfection of a plasmid encoding codon-optimized SARS-CoV-2 full-length S containing G614, a packaging plasmid pCMV $\triangle$ R8.2 expressing HIV gag and pol, and a luciferase reporter plasmid pHR' CMV-Luc. All plasmids were kindly provided by B. Graham (NIH, Vaccine Research Center). The 293T cell line stably overexpressing the human ACE2 protein was created by the Farzan group at Scripps Research Institute. For neutralization assays, serial dilutions of the ACE2 constructs were performed in duplicate followed by addition of pseudoviruses. Plates were incubated for $1 \mathrm{~h}$ at $37^{\circ} \mathrm{C}$ followed by addition of $293 \mathrm{~T} / \mathrm{ACE} 2$ target cells $\left(1 \times 10^{4}\right.$ per well). Wells containing cells and pseudoviruses without ACE2 proteins or cells alone were positive and negative infection controls, respectively. Assays were collected on day 3 using BrightGlo luciferase reagent (Promega) and luminescence detected with a Victor luminometer (PerkinElmer). $\mathrm{IC}_{50}$ values are reported as the ACE2 protein concentration that inhibited $50 \%$ of virus infection. All neutralization experiments were repeated twice with similar results.

Neutralization of authentic SARS-CoV-2. ACE2 variants were serially diluted in Dulbecco's PBS (Gibco) using half-log dilutions starting at $31,579 \mathrm{ng} \mathrm{ml}^{-1}$. Dilutions were prepared in triplicate for each protein. Each dilution was incubated at $37^{\circ} \mathrm{C}$ in $5 \% \mathrm{CO}_{2}$ for $1 \mathrm{~h}$ with 1,000 plaque forming units per $\mathrm{ml}\left(\mathrm{PFU} \mathrm{ml}{ }^{-1}\right)$ of SARS-CoV-2 (isolate USA-WA1/2020). Controls included DMEM (Gibco-Thermo Fisher Scientific) containing $2 \%$ fetal bovine serum (Gibco-Thermo Fisher Scientific) and antibiotic-antimycotic (Gibco-Thermo Fisher Scientific) only as a negative control, $1,000 \mathrm{PFU} \mathrm{ml}^{-1}$ SARS-CoV-2 (USA-WA1/2020) incubated with Dulbecco's PBS and $1,000 \mathrm{PFU} \mathrm{ml}^{-1}$ SARS-CoV-2 incubated with DMEM. For each dilution or control, $200 \mu \mathrm{l}$ was added to confluent monolayers of NR-596 Vero E6 cells in triplicate and incubated for $1 \mathrm{~h}$ at $37^{\circ} \mathrm{C}$ and $5 \% \mathrm{CO}_{2}$. The plates were gently rocked every 5-10 min to prevent monolayer drying. The monolayers were then overlaid with a 1:1 mixture of 2.5\% Avicel RC-591 microcrystalline cellulose and carboxymethylcellulose sodium (DuPont Nutrition \& Biosciences) and $2 \times$ MEM (Temin's modification, Gibco-Thermo Fisher Scientific), supplemented with $2 \times$ antibiotic-antimycotic, $2 \times$ GlutaMAX (Gibco-Thermo Fisher Scientific) and 10\% fetal bovine serum. Plates were incubated at $37^{\circ} \mathrm{C}$ and $5 \% \mathrm{CO}_{2}$ for $2 \mathrm{~d}$. The monolayers were fixed with $10 \%$ neutral buffered formalin and stained with $0.2 \%$ aqueous gentian violet (RICCA Chemicals) in $10 \%$ neutral buffered formalin for $30 \mathrm{~min}$, followed by rinsing and plaque counting. The $\mathrm{IC}_{50}$ values were calculated using GraphPad Prism 8.

Reporting Summary. Further information on research design is available in the Nature Research Reporting Summary linked to this article.

\section{Data availability}

The atomic structure coordinates and EM maps are deposited in the wwPDB and EMDB, respectively, under the accession numbers PDB 7KJ2 and EMD22891 (SARS-CoV-2 S in complex with one ACE2), PDB 7KJ3 and EMD-22892 (SARS-CoV-2 S in complex with two ACE2s), PDB 7KJ4 and EMD-22893

(SARS-CoV-2 S in complex with three ACE2s), and PDB 7KJ5 and EMD-22894 (SARS-CoV-2 S, no ACE2). Source data are provided with this paper.

\section{References}

48. Zheng, S. Q. et al. MotionCor2: anisotropic correction of beam-induced motion for improved cryo-electron microscopy. Nat. Methods 14, 331-332 (2017)

49. Rohou, A. \& Grigorieff, N. CTFFIND4: fast and accurate defocus estimation from electron micrographs. J. Struct. Biol. 192, 216-221 (2015).

50. Wagner, T. et al. SPHIRE-crYOLO is a fast and accurate fully automated particle picker for cryo-EM. Commun. Biol. 2, 218 (2019).

51. Scheres, S. H. RELION: implementation of a Bayesian approach to cryo-EM structure determination. J. Struct. Biol. 180, 519-530 (2012).

52. Emsley, P., Lohkamp, B., Scott, W. G. \& Cowtan, K. Features and development of Coot. Acta Crystallogr. D Biol. Crystallogr. 66, 486-501 (2010).

53. Adams, P. D. et al. PHENIX: a comprehensive Python-based system for macromolecular structure solution. Acta Crystallogr. D Biol. Crystallogr. 66, 213-221 (2010).

54. Croll, T. I. ISOLDE: a physically realistic environment for model building into low-resolution electron-density maps. Acta Crystallogr. D Struct. Biol. 74, 519-530 (2018).

55. Morin, A. et al. Collaboration gets the most out of software. Elife 2, e01456 (2013).

56. Millet, J. K. \& Whittaker, G. R. Murine Leukemia Virus (MLV)-based coronavirus spike-pseudotyped particle production and infection. Bio Protoc. 6, e2035 (2016).

57. Chen, C. Z. et al. Identifying SARS-CoV-2 entry inhibitors through drug repurposing screens of SARS-S and MERS-S pseudotyped particles. ACS Pharmacol. Transl. Sci. 3, 1165-1175 (2020).

\section{Acknowledgements}

We thank G. Frey for generous advice; S. Sterling, R. Walsh Jr. and S. Rawson for technical support; K. Arnett for advice on the BLI experiments; and S. Harrison for critical reading of the manuscript. EM data were collected at the Harvard Cryo-EM Center for Structural Biology of Harvard Medical School. This work was supported by NIH grant nos. AI147884 (to B.C.), AI147884-01A1S1 (to B.C), AI141002 (to B.C.) and AI127193 (to B.C. and J. Chou); a COVID19 Award by Massachusetts Consortium on Pathogen Readiness (MassCPR; to B.C.); as well as a Fast grant by Emergent Ventures (to B.C.).

\section{Author contributions}

J.L. and J.Z. contributed equally and R.I.J, L.G.A.M. and N.S. contributed equally. B.C. and T.X. conceived the project. T.X. designed, expressed and purified ACE2 variants with help from H.P. and Y.C. T.X. also performed binding experiments and enzymatic assays. J.L. carried out the neutralization assays using the MLV-based pseudoviruses and also designed and performed the AT1R activation experiments with contributions from S.L. J.Z. determined the cryo-EM structures of the ACE2-S complexes. R.I.J., L.G.A.M., N.S. and A.G. carried out the neutralization assays using SARS-CoV-2. C.L.L. and M.S.S. performed the neutralization assays using the HIV-based pseudoviruses. Y.C. also designed and produced the soluble S trimer. S.R.-V. contributed to cell culture for protein production. B.D.Q. and M.F. created the expression constructs for the dimeric ACE2 variants. All authors analyzed the data. B.C. and T.X. wrote the manuscript with input from all other authors.

\section{Competing interests}

Boston Children's Hospital has filed a patent application based on this work with B.C., T.X., J.Z. and Y.C. listed as coinventors. All other authors declare no competing interests.

\section{Additional information}

Extended data is available for this paper at https://doi.org/10.1038/s41594-020-00549-3.

Supplementary information is available for this paper at https://doi.org/10.1038/ s41594-020-00549-3.

\section{Correspondence and requests for materials should be addressed to B.C.}

Peer review information Nature Structural \& Molecular Biology thanks Brandon DeKosky and Xinquan Wang for their contribution to the peer review of this work. Inês Chen was the primary editor on this article and managed its editorial process and peer review in collaboration with the rest of the editorial team.

Reprints and permissions information is available at www.nature.com/reprints. 

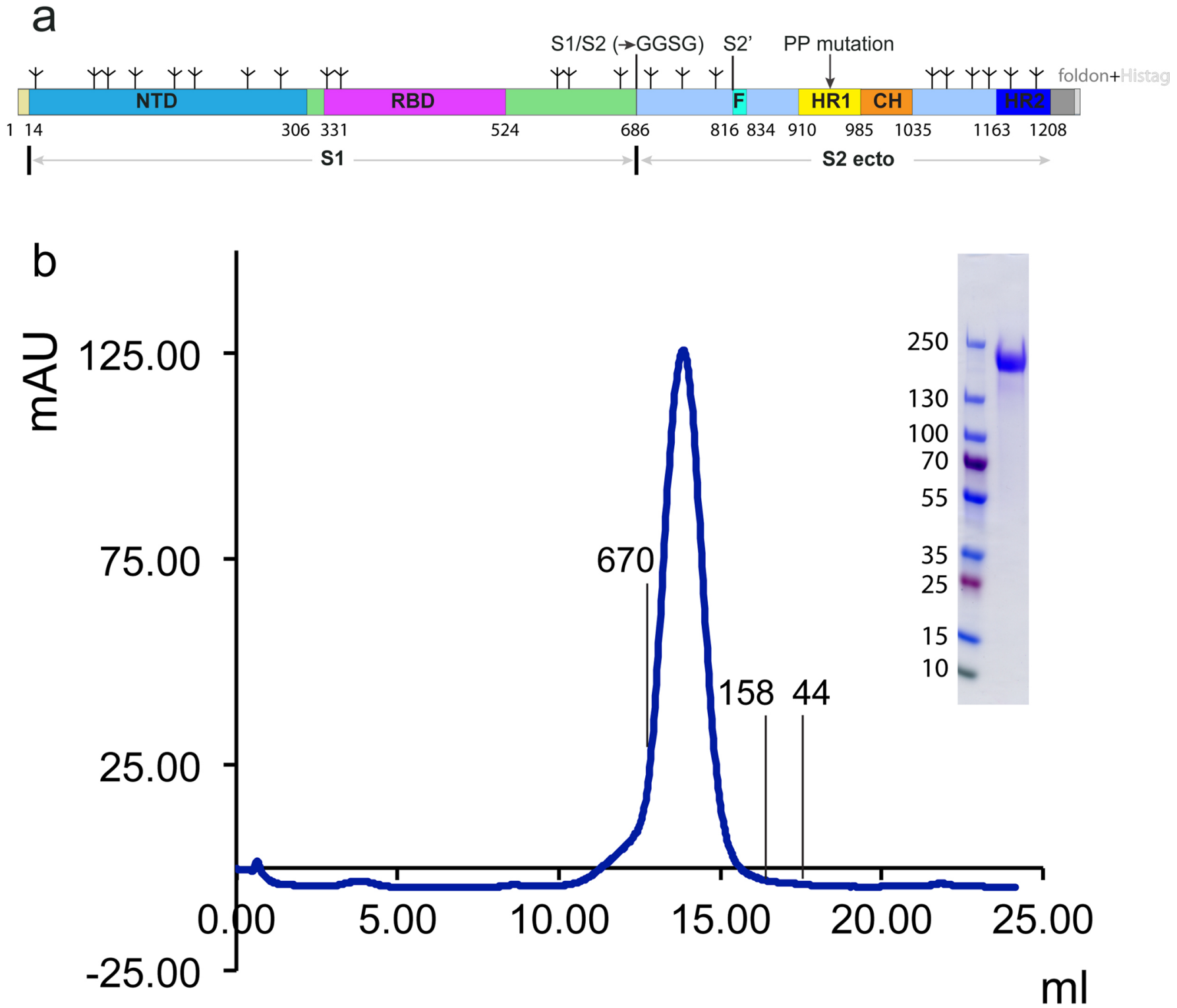

Extended Data Fig. 1 | Preparation of a stabilized soluble SARS-CoV-2 S trimer. a, Schematic representation of the expression construct of the soluble SARS-CoV-2 S protein. Segments of S1 and S2 ectodomain (S2ecto) include: NTD, N-terminal domain; RBD, receptor-binding domain; S1/S2, S1/S2 cleavage site; S2', S2' cleavage site; FP, fusion peptide; HR1, heptad repeat 1; CH, central helix region; HR2, heptad repeat 2; and tree-like symbols for glycans. The S1/S2 cleavage site (RRAR) was mutated to GGSG. Two mutations K986P and V987P were introduced and a trimerization tag -foldon fused to the $\mathrm{C}$-terminal end to stabilize the prefusion conformation ${ }^{29}$. A C-terminal histag was included for protein purification. $\mathbf{b}$, The purified $\mathrm{S}$ protein was resolved by gel-filtration chromatography on a Superose 6 column and the pooled peak fractions were analyzed by Coomassie stained SDS-PAGE. The molecular weight standards include thyoglobulin $(670 \mathrm{kDa}), \gamma$-globulin $(158 \mathrm{kDa})$ and ovalbumin $(44 \mathrm{kDa})$. The uncropped image for panel $\mathrm{b}$ is available as source data. 

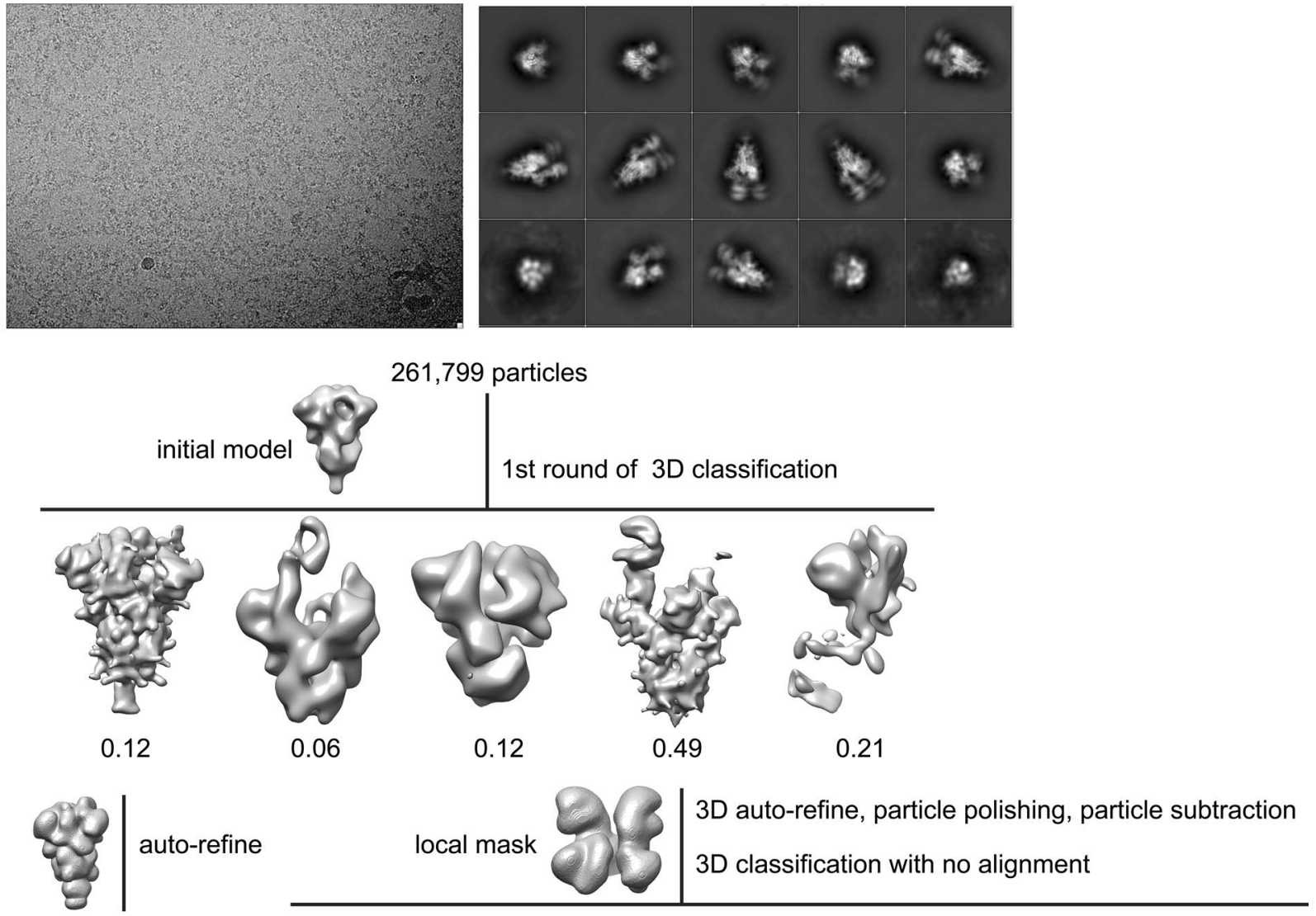

overall mask

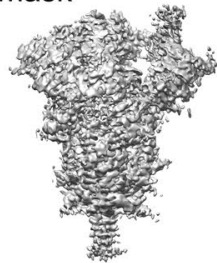

32,685 particles no ACE2; $3.6 \AA$

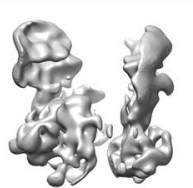

0.13

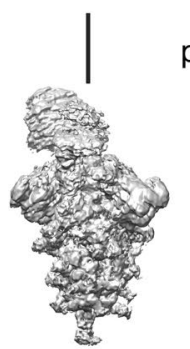

0.10
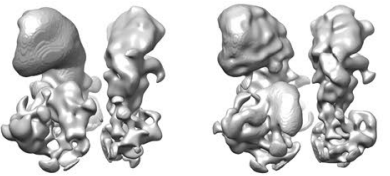

0.19

particle | re-extraction
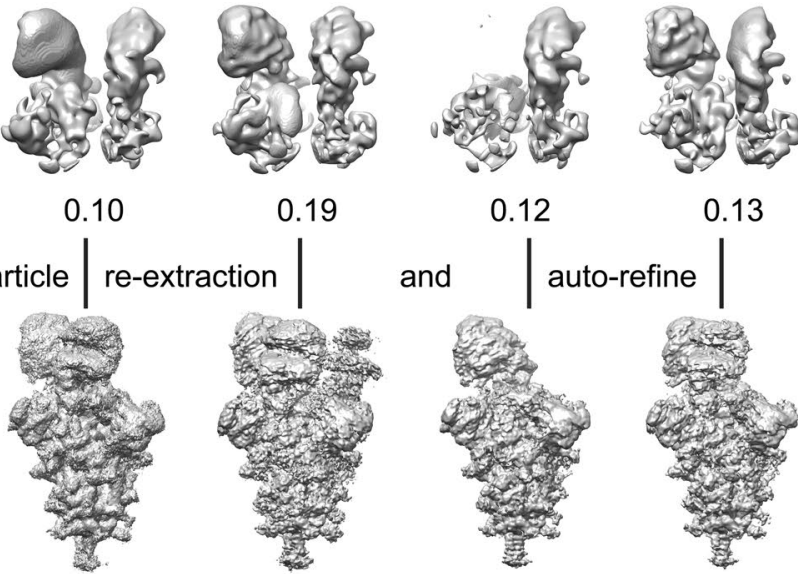

0.13

0.12<smiles>C[13CH][13CH][13CH][13CH]</smiles>
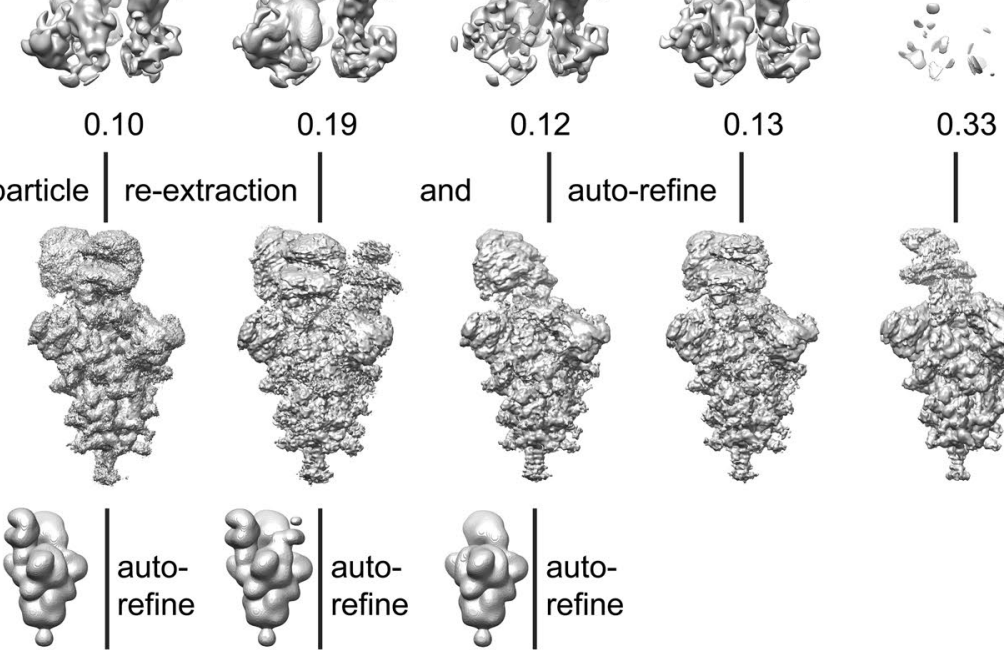

overall mask overall mask overall mask
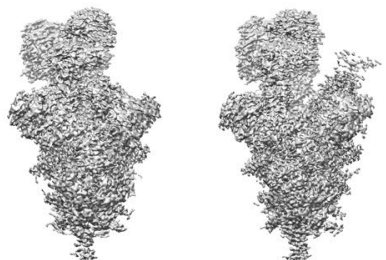

26,298 particles 3 ACE2; $3.4 \AA$

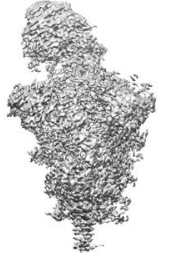

15,964 particles 1 ACE2; 3.6尺

Extended Data Fig. 2 | See next page for caption. 
Extended Data Fig. 2 | Cryo-EM analysis of the ACE2-S complexes. Top, representative micrograph, and 2D averages of the cryo-EM particle images showing secondary structural features. Bottom, data processing workflow for structures of the free S trimer (no ACE2), S trimer with one ACE2 bound (1 ACE2), S trimer with two ACE2 bound (2 ACE2), S trimer with three ACE2 bound (3 ACE2), as indicated. 
a
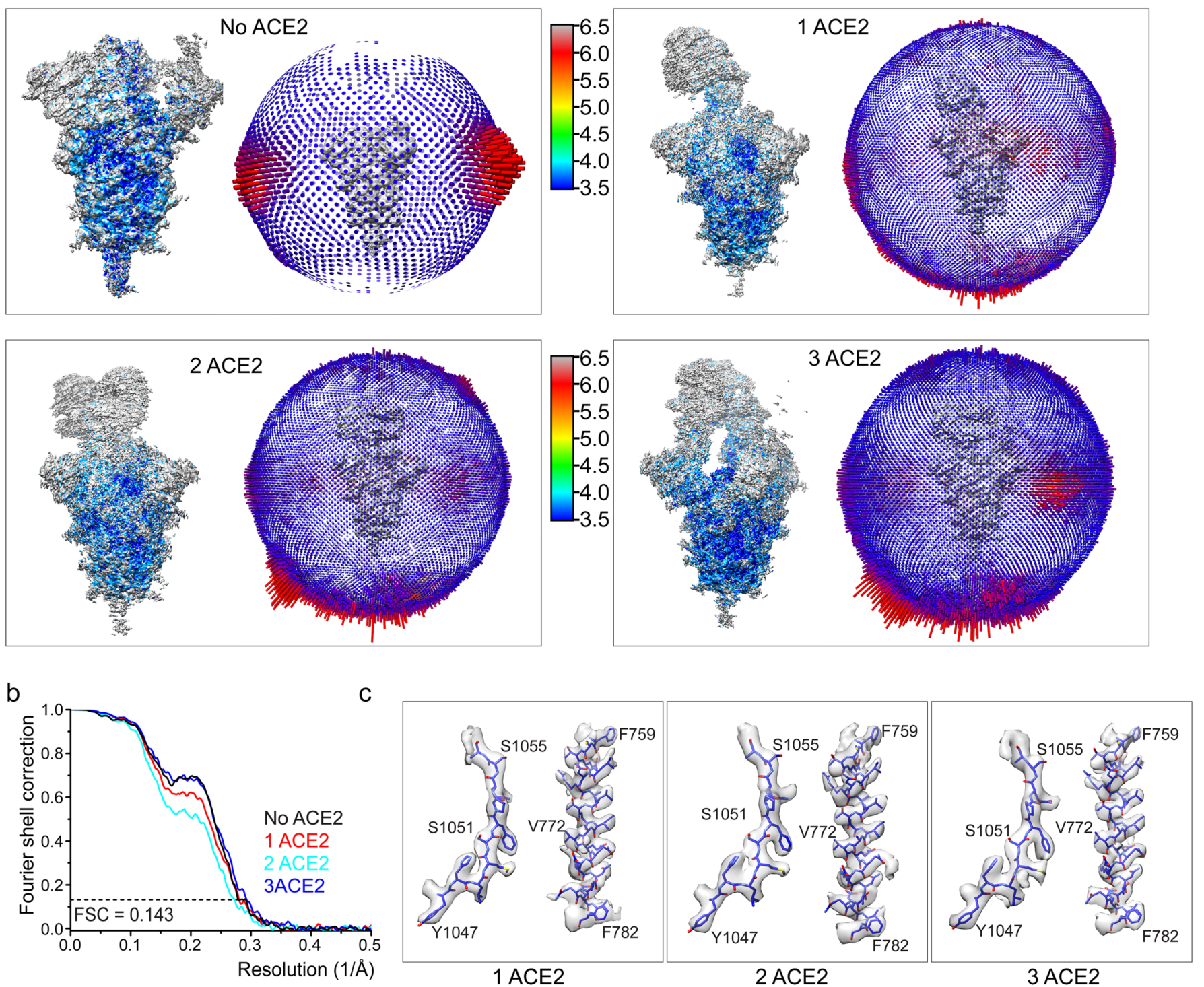

Extended Data Fig. 3 | Analysis of the 3D reconstructions of the S-ACE2 complexes. a, 3D reconstructions of the S trimer and its ACE2 complexes are colored according to local resolution estimated by RELION. Angular distribution of the cryo-EM particles used in the reconstruction is shown in the side view of the EM map. $\mathbf{b}$, Gold standard FSC curves of the refined 3D reconstructions. c, Representative density in gray surface from the EM maps. No ACE2), the free S trimer; 1 ACE2, S trimer with one ACE2 bound; 2 ACE2, S trimer with two ACE2 bound; 3 ACE2, S trimer with three ACE2 bound. 
a

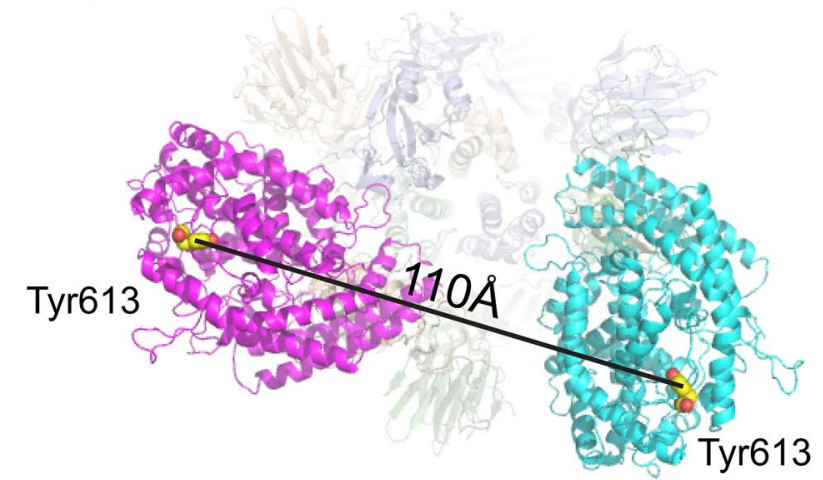

b

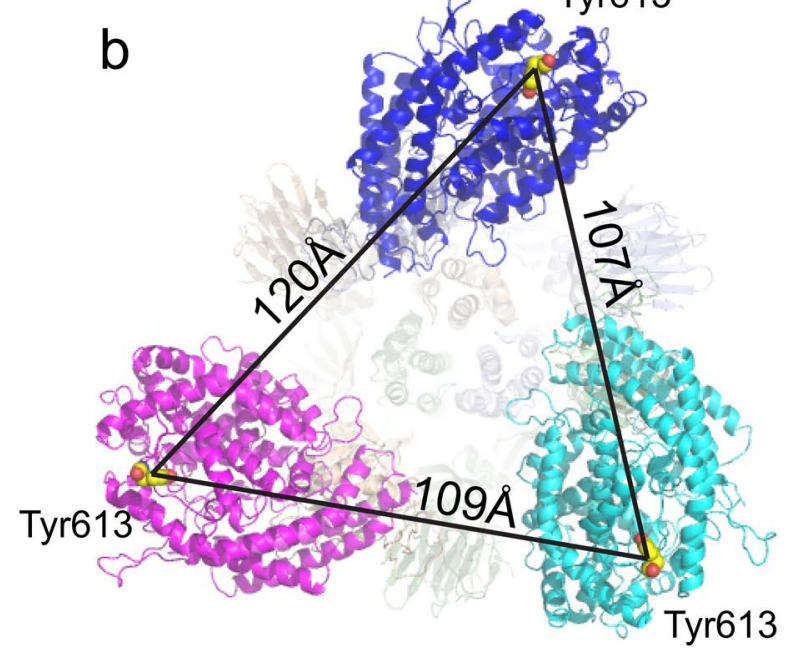

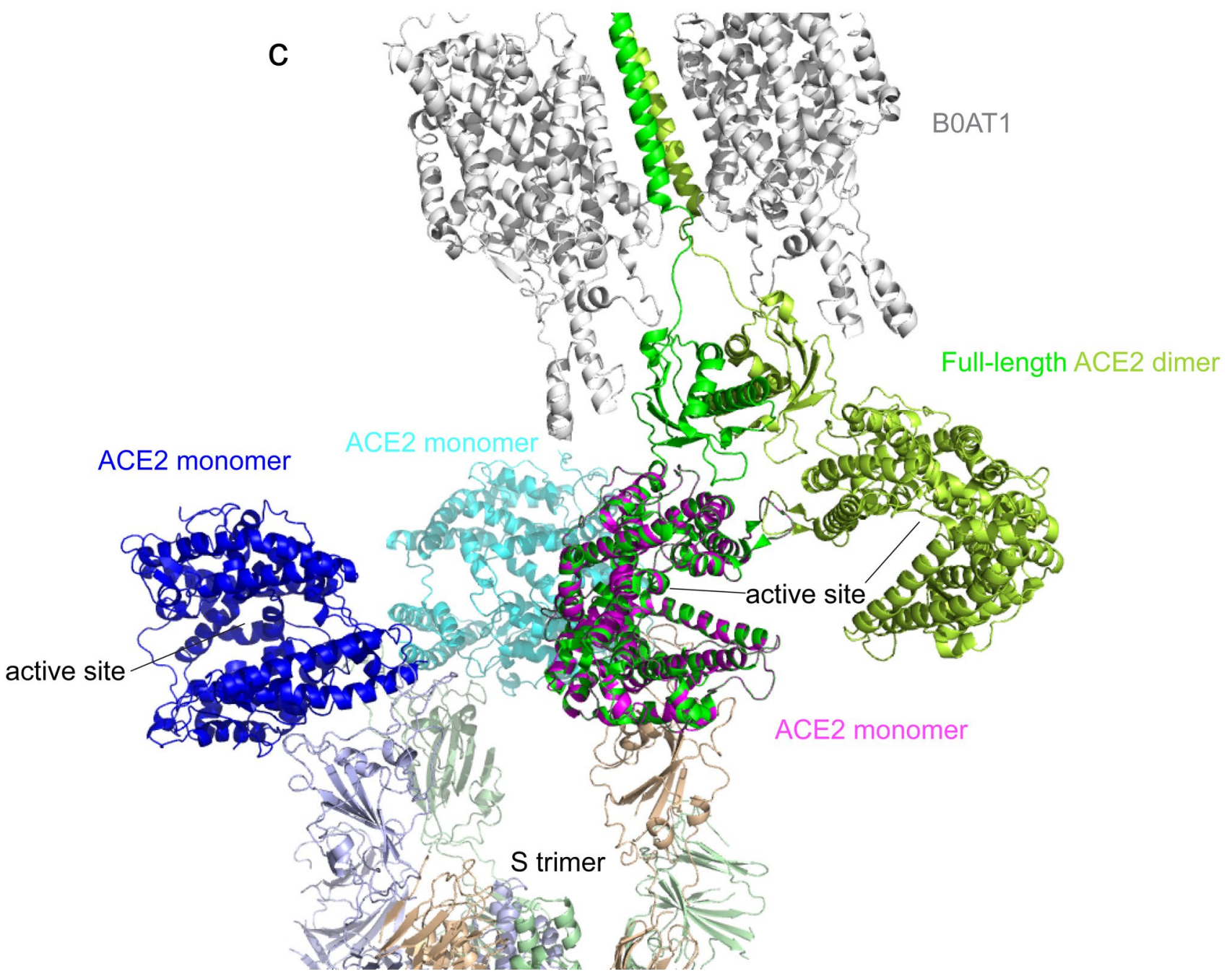

Extended Data Fig. 4 | ACE2-S interactions. a, The top view of the $\mathrm{S}$ trimer in complex with two monomeric ACE2 molecules (in magenta and cyan, respectively) with the distance between the C-terminal ends of the ACE2s indicated. $\mathbf{b}$, The top view of the $\mathrm{S}$ trimer in complex with three monomeric ACE2 molecules (in magenta, blue and cyan, respectively) with the distances between the C-terminal ends of the ACE2s indicated. $\mathbf{c}$, Superposition of the structure of the full-length ACE2 (PDB 6M17) and the structure of S-3 ACE2 complex. 

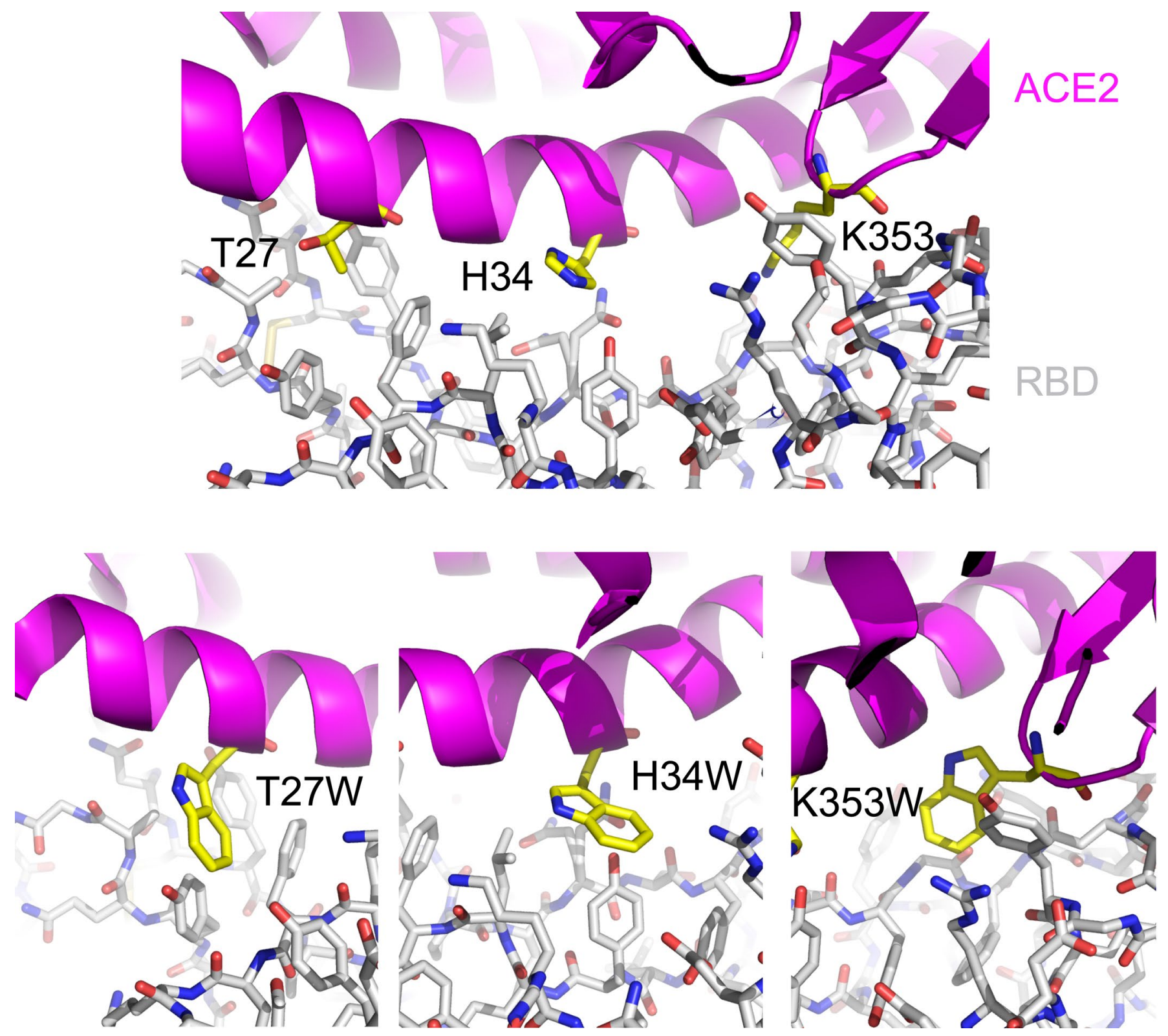

Extended Data Fig. 5 | Design of mutations at the ACE2-RBD interface. Top, the interface between ACE2 in ribbon diagram in magenta and RBD in stick model from the complex structure (PDB 6MOJ) with T27, H34 and K353 from ACE2 indicated. Bottom, modeled T27W, H34W and K353W mutations that may enhance the hydrophobic interactions between ACE2 and RBD. 

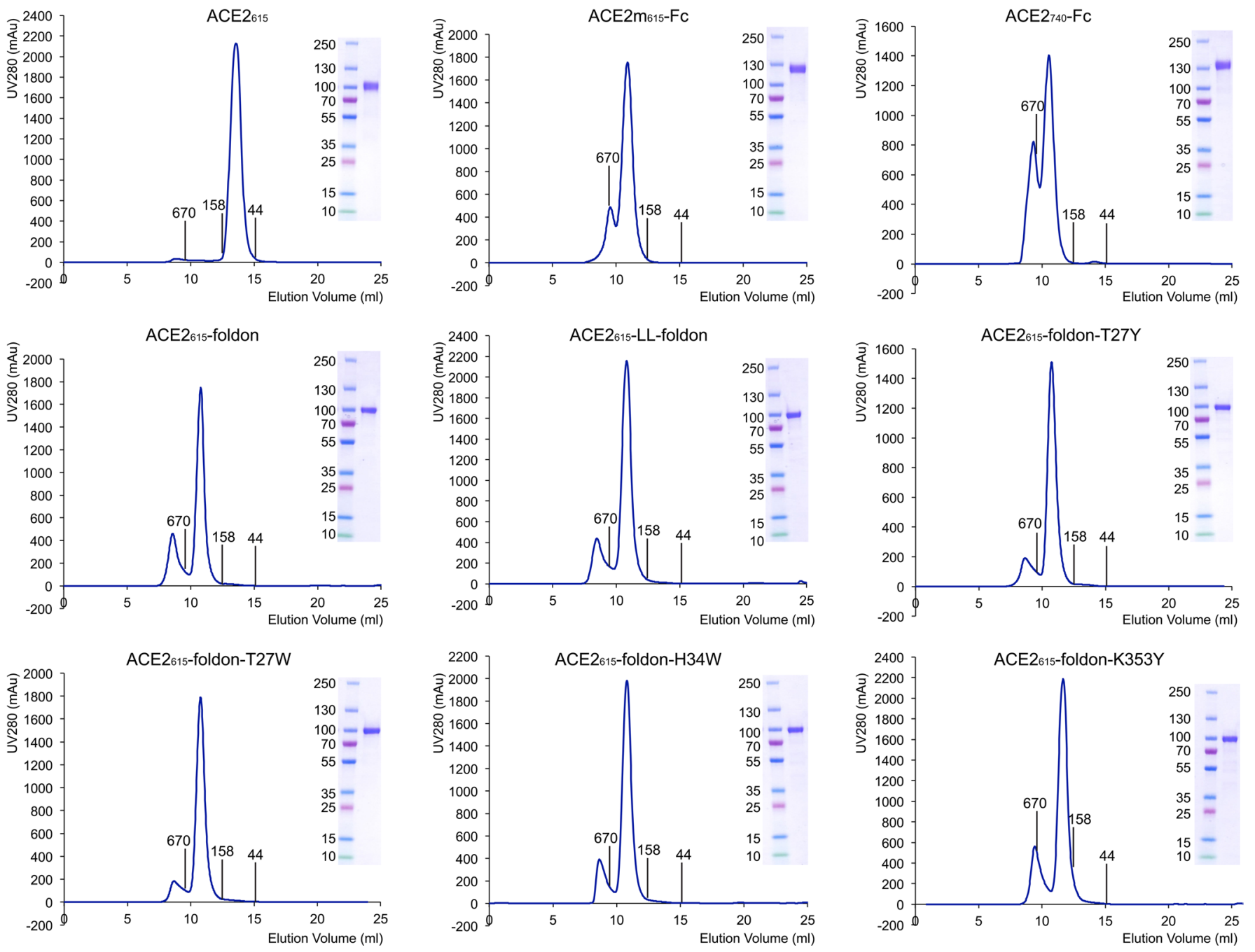

Extended Data Fig. 6 | Purification of ACE2 variants. The purified ACE2 proteins were resolved by gel-filtration chromatography on a Superdex 200 column. The molecular weight standards include thyoglobulin $(670 \mathrm{kDa}), \gamma$-globulin ( $158 \mathrm{kDa})$ and ovalbumin $(44 \mathrm{kDa})$. Inset, peak fractions were analyzed by Coomassie stained SDS-PAGE. The uncropped image is available as source data. 
a

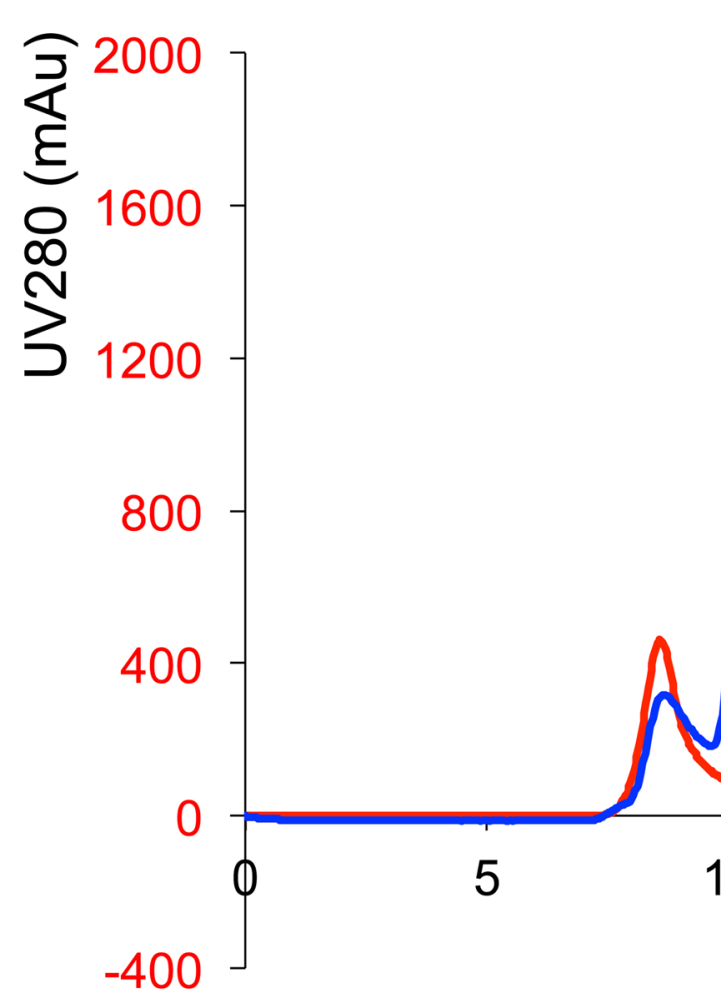

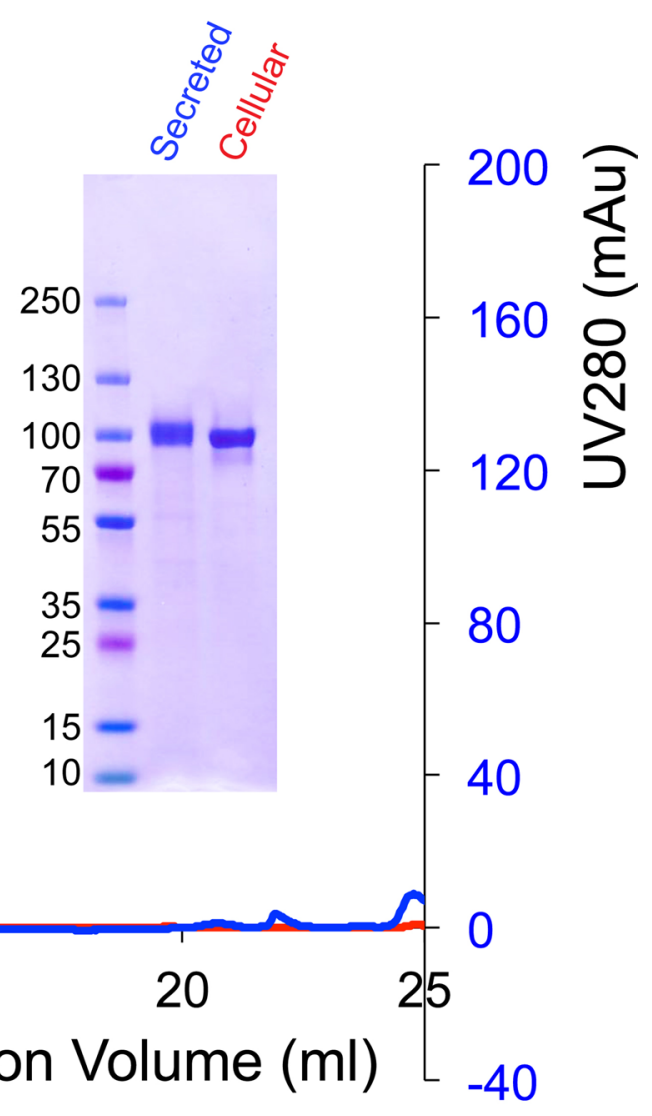

b

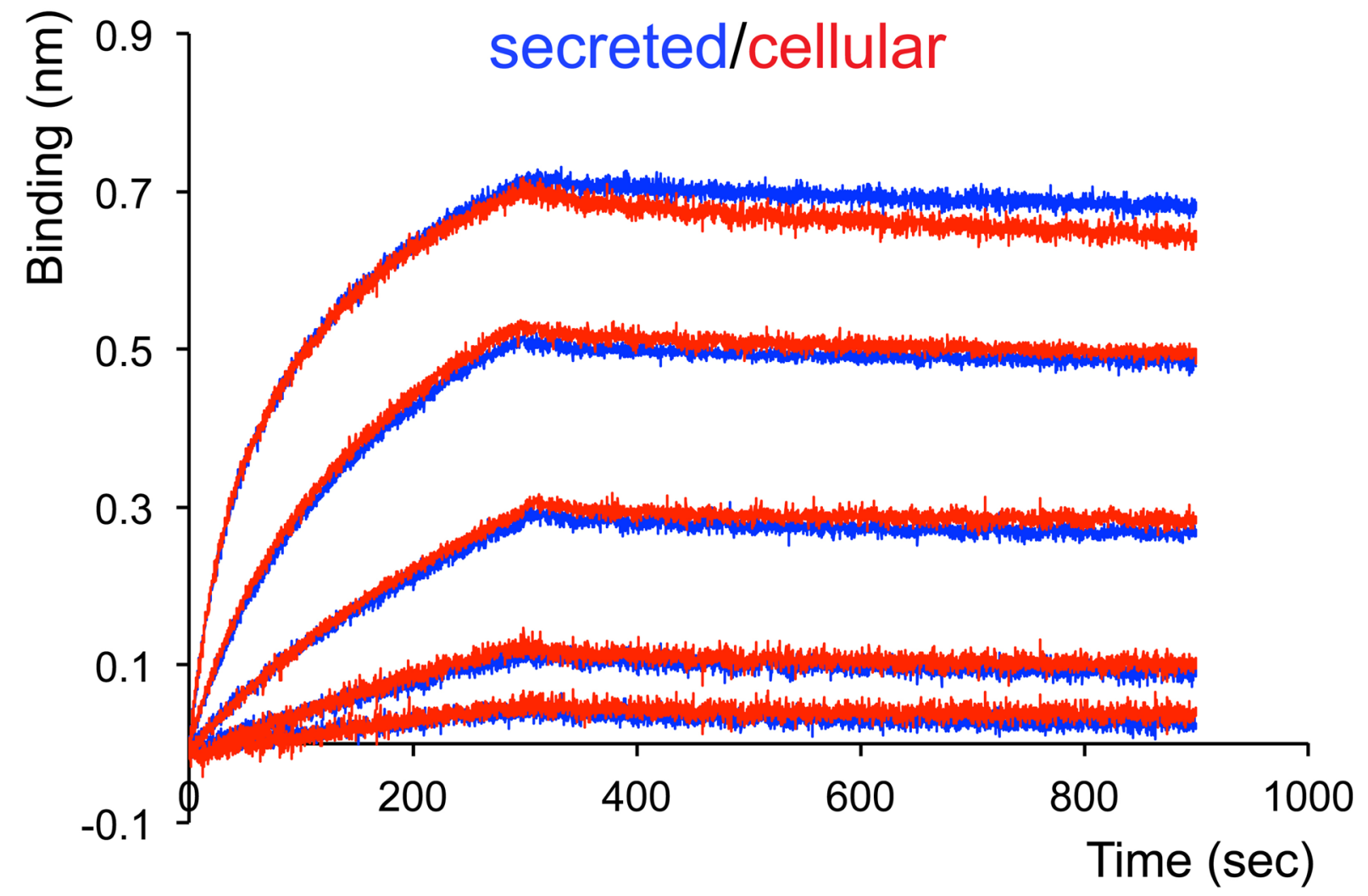

Extended Data Fig. 7 | See next page for caption. 
Extended Data Fig. 7 | Comparison of secreted and cellular ACE2 ${ }_{615}$-foldon protein. $\mathbf{a}$, The purified ACE2 615 -foldon protein either from cell supernatants (secrected) or cell lysates (cellular) was resolved by gel-filtration chromatography on a Superdex 200 column. Inset, peak fractions were analyzed by Coomassie stained SDS-PAGE. The uncropped image for panel a is available as source data. $\mathbf{b}$, Binding of ACE2 ${ }_{615}$-foldon to the stabilized soluble $\mathbf{S}$ trimer by bio-layer interferometry (BLI). The $S$ protein was immobilized and subsequently dipped into the wells containing either secreted or cellular ACE2 ${ }_{615}$-foldon at various concentrations $(0.617-50 \mathrm{nM})$. The sensorgrams for the secreted ACE2 ${ }_{615}$-foldon are in blue and those for the cellular ACE2 615 -foldon in red. 

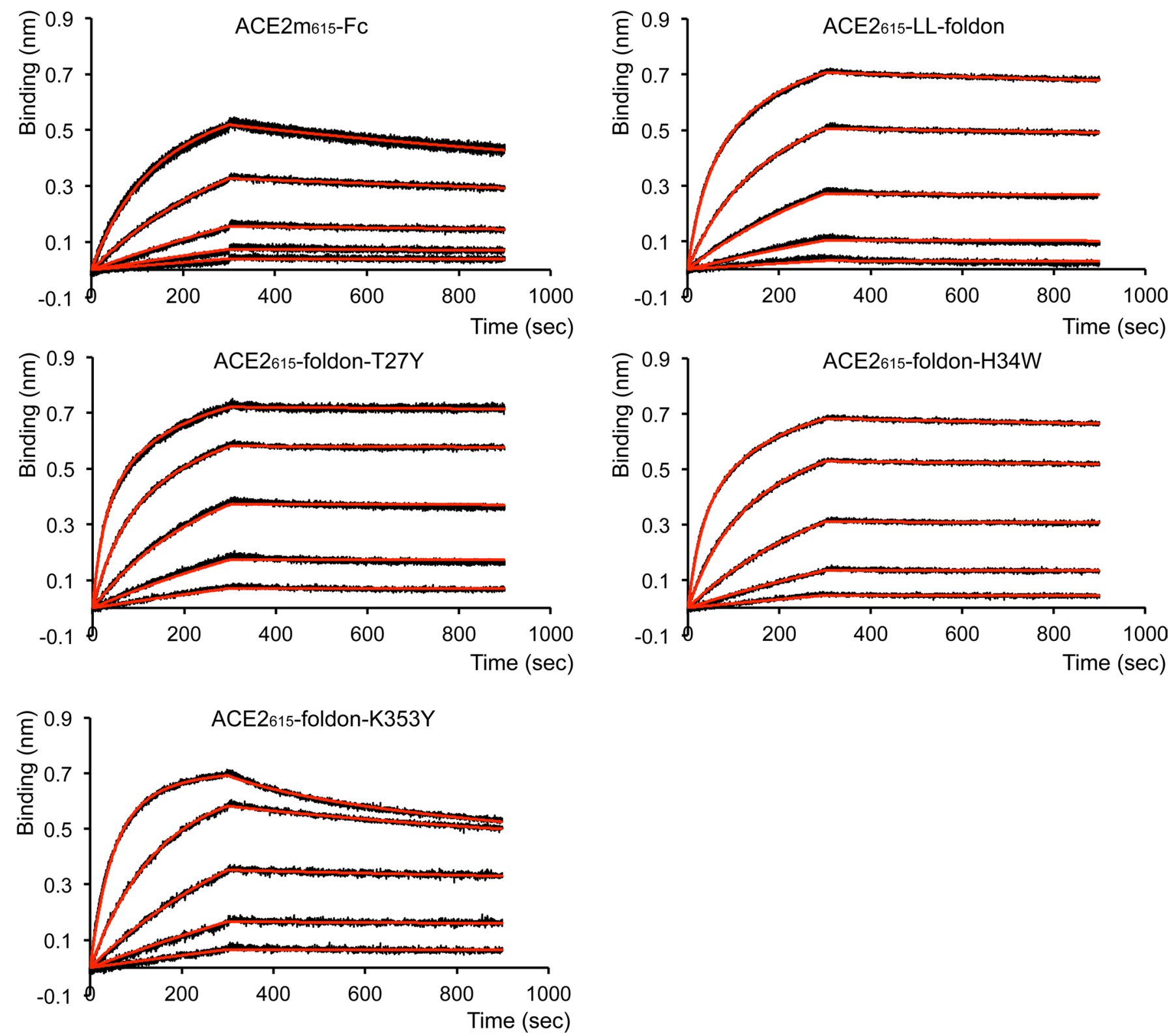

Extended Data Fig. 8 | Binding of ACE2 variants to the stabilized soluble S trimer by bio-layer interferometry (BLI). The S protein was immobilized and subsequently dipped into the wells containing ACE2 proteins at various concentrations $\left(0.926-75 \mathrm{nM}\right.$ for $A C E 2_{615}-\mathrm{Fc}_{1} 0.617-50 \mathrm{nM}$ for the $\mathrm{ACE} 2_{615}$-foldon variants). Binding kinetics was evaluated using a bivalent model for all oligomeric ACE2s. The sensorgrams are in black and the fits in red. All the experiments were repeated at least twice with essentially identical results. Binding constants derived from the BLI experiments are summarized in Supplementary Table 3. 


\section{Reporting Summary}

Nature Research wishes to improve the reproducibility of the work that we publish. This form provides structure for consistency and transparency in reporting. For further information on Nature Research policies, see our Editorial Policies and the Editorial Policy Checklist.

\section{Statistics}

For all statistical analyses, confirm that the following items are present in the figure legend, table legend, main text, or Methods section.

$\mathrm{n} / \mathrm{a}$ Confirmed

$\bigotimes$ The exact sample size $(n)$ for each experimental group/condition, given as a discrete number and unit of measurement

$\square$ A statement on whether measurements were taken from distinct samples or whether the same sample was measured repeatedly

The statistical test(s) used AND whether they are one- or two-sided

Xnly common tests should be described solely by name; describe more complex techniques in the Methods section.

$\triangle \square$ A description of all covariates tested

Х $\square$ A description of any assumptions or corrections, such as tests of normality and adjustment for multiple comparisons

A full description of the statistical parameters including central tendency (e.g. means) or other basic estimates (e.g. regression coefficient)

X AND variation (e.g. standard deviation) or associated estimates of uncertainty (e.g. confidence intervals)

$\triangle$ For null hypothesis testing, the test statistic (e.g. $F, t, r$ ) with confidence intervals, effect sizes, degrees of freedom and $P$ value noted

\} \square \text { Give } P \text { values as exact values whenever suitable. }

Х $\square$ For Bayesian analysis, information on the choice of priors and Markov chain Monte Carlo settings

Х $\square$ For hierarchical and complex designs, identification of the appropriate level for tests and full reporting of outcomes

Х $\square$ Estimates of effect sizes (e.g. Cohen's $d$, Pearson's $r$ ), indicating how they were calculated

\section{Our web collection on statistics for biologists contains articles on many of the points above.}

\section{Software and code}

Policy information about availability of computer code

Data collection SerialEM, Octet RED384

Data analysis EMAN2, CrYOLO, MotionCor2, CTFFIND4, RELION, Coot, Chimera, Phenix, Octet Data Analysis HT Version 11.1.

For manuscripts utilizing custom algorithms or software that are central to the research but not yet described in published literature, software must be made available to editors and

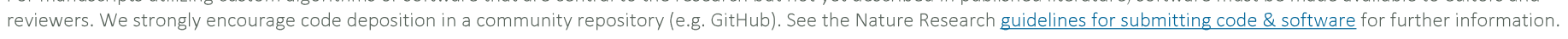

\section{Data}

Policy information about availability of data

All manuscripts must include a data availability statement. This statement should provide the following information, where applicable:

- Accession codes, unique identifiers, or web links for publicly available datasets

- A list of figures that have associated raw data

- A description of any restrictions on data availability

The atomic structure coordinates and EM maps are deposited in the EMDataBank under the accession number xxxx. All other related data generated during and/or analyzed during the current study are available from the corresponding author on reasonable request. 
Please select the one below that is the best fit for your research. If you are not sure, read the appropriate sections before making your selection.

$\bigotimes$ Life sciences $\quad \square$ Behavioural \& social sciences $\quad \square$ Ecological, evolutionary \& environmental sciences

For a reference copy of the document with all sections, see nature.com/documents/nr-reporting-summary-flat.pdf

\section{Life sciences study design}

All studies must disclose on these points even when the disclosure is negative.

Sample size No statistical methods were used to predetermine sample size.

Data exclusions No data were excluded from analyses.

Replication Multiple EM data sets were collected with very similar quality. All other experiments have been repeated multiple times with excellent reproducibility.

Randomization Experimental groups are not needed for this work, therefore randomization is not relevant.

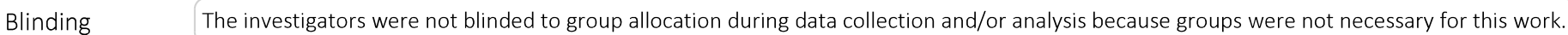

\section{Reporting for specific materials, systems and methods}

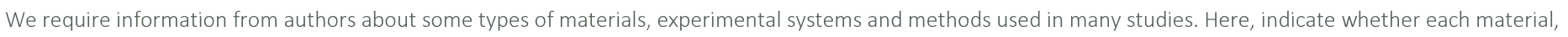

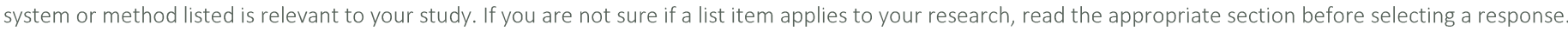

\begin{tabular}{|c|c|}
\hline$n / a$ & Involved in the study \\
\hline$\bigotimes$ & $\square$ Antibodies \\
\hline L & 区ukaryotic cell lines \\
\hline Х & $\square$ Palaeontology and archaeology \\
\hline$\bigotimes$ & $\square$ Animals and other organisms \\
\hline Х & $\square$ Human research participants \\
\hline$\bigotimes$ & $\square$ Clinical data \\
\hline Х & $\square$ Dual use research of concern \\
\hline
\end{tabular}

Methods n/a Involved in the study

Х $\square$ Chip-seq

Х $\square$ Flow cytometry

\ $\square$ MRI-based neuroimaging

\section{Eukaryotic cell lines}

Policy information about cell lines

Cell line source(s)

HEK 293T cells were purchased from ATCC; Expi293F from Thermo Fisher Scientific.

Authentication

Each cell line was authenticated for protein production by western blot and protein purification.

Mycoplasma contamination

Mycoplasma contamination is routinely tested for our cell culture and no contaminated cells were ever used for our studies.

Commonly misidentified lines

(See ICLAC register)

None. 